\title{
Mouse Genetic Models of Human Brain Disorders
}

\author{
Celeste Leung ${ }^{1,2}$ and Zhengping Jia ${ }^{1,2 *}$ \\ ${ }^{1}$ The Hospital for Sick Children, Program in Neurosciences and Mental Health, Peter Gilgan Centre for Research and \\ Learning, Toronto, ON, Canada, ${ }^{2}$ Program in Physiology, University of Toronto, Toronto, ON, Canada
}

Over the past three decades, genetic manipulations in mice have been used in neuroscience as a major approach to investigate the in vivo function of genes and their alterations. In particular, gene targeting techniques using embryonic stem cells have revolutionized the field of mammalian genetics and have been at the forefront in the generation of numerous mouse models of human brain disorders. In this review, we will first examine childhood developmental disorders such as autism, intellectual disability, Fragile $X$ syndrome, and Williams-Beuren syndrome. We will then explore psychiatric disorders such as schizophrenia and lastly, neurodegenerative disorders including Alzheimer's disease and Parkinson's disease. We will outline the creation of these mouse models that range from single gene deletions, subtle point mutations to multi-gene manipulations, and discuss the key behavioral phenotypes of these mice. Ultimately, the analysis of the models outlined in this review will enhance our understanding of the in vivo role and underlying mechanisms of disease-related genes in both normal brain function and brain disorders, and provide potential therapeutic targets and strategies to prevent and treat these diseases.

Edited by:

Robert Gerlai,

University of Toronto, Canada

Reviewed by:

Rafael Fernández-Chacón, The Neuroscience Institute at Seville,

Spain

Keywords: genetic models, transgenic mice, gene targeting, knockout, knock-in, inducible, brain disorders, behavior

The advent of genomic manipulation in mice began in the early 1980s through the microinjection of exogenous DNA into the pronuclei of fertilized eggs that randomly integrate into the mouse genome. These embryos were surgically transferred into pseudopregnant recipient females, resulting in the birth of transgenic mice harboring Mendelian inheritable traits. In particular, this invaluable technique has allowed for the stable integration of genetic information into the mouse genome. Therefore, over the last 30 years, the use of transgenic mice has dramatically increased our understanding of certain disease-related genes and the consequences of ablating specific cell types or introducing genetic mutations associated with particular human diseases. Recent advances have also employed inducible and cell-type restricted expression systems, thus enhancing the utility of transgenic mice. However, transgenic models have certain limitations. In particular, the copy number and site of integration of the transgene in the mouse genome is random and therefore, cannot be controlled, often resulting in non-specific spatial and temporal expression of the transgene. To address these limitations, a gene targeting approach was created in the late 1980s that utilizes pluripotent embryonic stem (ES) cells, which allows for specific and targeted changes of the endogenous genome. This technique combined with site-directed mutagenesis and the bacteriophage Cre/loxP system has allowed for diverse, controlled, and precise manipulations of genes of interest. In this approach, a targeting vector with desired deletions/mutations is introduced into ES cells and undergoes homologous recombination with the endogenous wild-type allele, resulting in deletion (knockout) or replacement (knock-in) of the wild-type copy of the 
gene. The correctly targeted ES cells are selected and then injected to a recipient pseudopregnant foster female to generate chimeras. These chimeras are then tested for germline transmission and homozygosity for the targeted changes. Although, both forward and reverse genetic mouse models have contributed to significant advancements in biological research and a broad range of clinical applications (Schughart et al., 2013), we will focus this review on transgenic and gene targeting techniques that have been employed in the generation of animal models of human brain disorders, with particular focus on autism, intellectual disability (ID), Fragile X syndrome (FXS), Williams- Beuren syndrome, schizophrenia, Alzheimer's disease (AD), and Parkinson's disease (PD). Specifically, we will discuss the methods and approaches used to create the mouse models, the major phenotypes of these models, and implications of these findings. For each disorder, we will focus on several well-studied disease models and their behavioral outcomes, to illustrate the power of genetic alterations in mice as a model system to understand the diseases. However, this review will not discuss animal models of brain diseases based on other approaches such as those using environmental and/or pharmacological perturbations. Ultimately, the models discussed will enhance our understanding of the underlying mechanisms in disease pathogenesis, and offer insights that can translate animal studies to a clinical setting.

\section{AUTISM SPECTRUM DISORDERS}

Autism spectrum disorders (ASDs) are amongst the most prevalent childhood disorders, affecting 1 in every 68 children within North America (Bolivar, 2014). ASD is a developmental disability that includes a broad spectrum of neurodevelopmental diseases including autism, Asperger's disorder, Rett syndrome, childhood disintegrative disorder, and pervasive developmental disorder. Amongst these, autism remains the most common ASD. As characterized by DSM-V, children diagnosed with autism have severe social interaction impairments, accompanied by concrete social communication deficits, and stereotyped or repetitive behaviors. Therefore, as one of the leading socioeconomic healthcare problems, there has been ongoing effort to identify genetic biomarkers and to elucidate their mechanisms to treat the triad of impairments associated with this neurodevelopmental disorder. Through genetic screening and post-mortem studies, various candidate genes have been identified to be associated with autism. This section will primarily focus on four wellstudied mouse models relevant to autism and the behavioral outcomes relevant to this complex disorder. These models are prime examples of how targeting autism-related genes in mice can be a useful tool to investigate the cellular and molecular processes underlying the behavioral consequences of this complex disorder.

\section{Neurexins}

The neurexin family (NRXN1-3) of presynaptic plasma membrane proteins are trans-synaptic cell adhesion molecules that connect functionally pre- and post-synaptic neurons at synapses (Sudhof, 2008; Rabaneda et al., 2014). The extracellular domain of NRXNs interacts with post-synaptic neuroligins (NLGN1-4) across the synaptic cleft and have an essential role in synaptic regulation (Sudhof, 2008; Rabaneda et al., 2014). Each NRXN gene in mammals is composed of differentially distributed long $\alpha$ - and short $\beta$-NRXN isoforms. Together, NRXNs and NLGNs are required for proper synapse maturation and trans-synaptic neurotransmission (Varoqueaux et al., 2006; Sudhof, 2008). Current gene association studies reveal that hypofunction of NRXN isoforms, specifically rare single gene variations in NRXN1, are linked to autism. Since, $0.5 \%$ of all ASD cases appear to harbor NXRXN-1 $\alpha$ gene deletions, Etherton et al. (2009) generated NRXN1 $\alpha$ knockout (KO) to uncover the behavioral and functional consequences of this gene deletion. NRXN1 $\alpha$ KO mice were generated by deleting the promoter and large first exon of the murine $\alpha$-NRXN genes (Tabuchi and Sudhof, 2002; Missler et al., 2003). These KO mice were found to have impaired excitatory synaptic strength, decreased prepulse inhibition, increased grooming behavior, and enhanced motor learning (Etherton et al., 2009). The authors proposed that $\mathrm{NRXN1} \alpha$ is responsible for regulating a proper excitatory to inhibitory balance in synaptic transmission and various behavioral phenotypes related to autism. In addition, recent studies demonstrate that the heterozygous deletion of NRXN1 $\alpha$ also resulted in impaired social memory salient with behaviors relevant to autism (Dachtler et al., 2015). In another study, Rabaneda et al. (2014) generated a deletion mutant to target the NRXN1 $\beta$ isoform that lacks the cytoplasmic tail to uncouple NRXN1 $\beta$ trans-synaptic function. Transgenic hemagglutinin (HA)- tagged $\beta N R X N 1 \Delta C$ were expressed in an inducible manner under the control of a tetracycline-responsive promoter element (TRE). The TRE-HA $\beta$ NRXN1 $\Delta \mathrm{C}$ mice were crossed with a CaMKII $\alpha$-tTA promoter to restrict the expression of the mutant protein in mature glutamatergic neurons in the forebrain. As expected, the double transgenic CaMKII $\alpha$-tTA TRE-HA $\beta N R X N 1 \Delta \mathrm{C}$ mice expressed the mutant protein in forebrain neurons of the cortex and striatum (Rabaneda et al., 2014). These mice displayed increased self-grooming and deficits in social interactions, consistent with the triad of autism-related symptoms (Rabaneda et al., 2014). However, with the administration of the tetracycline analog, doxycycline (DOX), in the drinking water, the expression of HA- $\beta$ NRXN1 $\triangle \mathrm{C}$ was suppressed. The autistic-like phenotypes were reversed following DOX administration thereby suggesting that NRXNs regulate functional and behavioral activity in mature neurons. These results suggest that the presynaptic NRXN1 may cause autistic phenotypes via interacting with its post-synaptic partner NLGNs, altering excitatory synaptic function.

\section{Contactin-Associated Protein 2}

Contactin-associated protein 2 (CNTNAP2), a member of the NRXN super family, encodes a neuronal transmembrane protein (CASPR2) involved in the formation of tight axonal connections critical for the establishment and maintenance of neuronal circuits (Rodenas-Cuadrado et al., 2014; Gdalyahu et al., 2015). CASPR2 is localized in juxtaparanodes of myelinated axons and mediates interactions between neurons and glia during development (Poliak et al., 1999). In vitro studies have 
shown that RNAi-mediated knock-down of CASPR2 impairs the development and maturation of dendritic spines resulting in decreased synaptic transmission (Anderson et al., 2012). Moreover, the loss of function of CASPR2 led to impaired synaptic connectivity and neural network assembly. Alterations in the CNTNAP2 gene are strongly linked to language deficits in complex neurological disorders including autism, specifically in patients with a single nucleotide polymorphism in intron 2 of the CNTNAP2 gene (rs7794735; Arking et al., 2008). In mice, ablation of CNTNAP2 resulted in fewer GABAergic interneurons, neuronal migration abnormalities, and reduced cortical neuronal synchrony (Penagarikano et al., 2011). In addition, it was found that the intermodal localization of $\mathrm{Kv} 1$ channels at the juxtaparanodal region depends on the presence of CNTNAP2 (Gordon et al., 2014). Behaviorally, CASPR2 KO mice exhibited core autism-like symptoms including lower levels of sociability and decreased ultrasonic vocalizations with increased levels of grooming, hyperactivity, and deficits in reversibility on the Morris water maze test. In a recent study, CNTNAP2 $\mathrm{KO}$ mice were found to have reduced spine density due to increased spine elimination and impaired stabilization of new spines (Gdalyahu et al., 2015). Therefore, these results together suggest the importance of CNTNAP2 in neuronal migration and formation of cortical neural networks that may underlie the behavioral responses. In particular, the decreased GABAergic interneuron activity may imply that neural asynchrony or an excitatory and inhibitory imbalance may be a pathophysiological mechanism to explain how information processing is impaired in autism.

\section{Neuroligins}

Neuroligins (NLGN1-3, 4X, 4Y) are a family of post-synaptic cell adhesion molecules that are ligands of their trans-synaptic partner NRXN (Ichtchenko et al., 1995; Autism Genome Project et al., 2007; Kim et al., 2008). Human genetic association studies have linked changes in the NLGN genes with autism (Sudhof, 2008; Glessner et al., 2009). Therefore, mouse models that target each of the different NLGN isoforms have been generated to better understand the in vivo function of these genes and how their mutations contribute to autism-like behaviors. $\mathrm{KO}$ mice lacking individual NLGNs were created through the deletion of exon sequences spanning the translational start site and $380 \mathrm{bp}$ of the $5^{\prime}$ coding sequence of the respective genes via homologous recombination in ES cells (Varoqueaux et al., 2006). The deletion of the NLGN1 gene, whose expression is localized at excitatory synapses, resulted in decreased NRXN1 levels, reduced excitatory transmission, and selective deficits in social memory, spatial learning and memory tests, and increases in grooming (Blundell et al., 2010). However, these authors did find a 30\% increase in the expression of NLGN3, suggesting a functional compensation between members of the NLGN family (Blundell et al., 2010). Moreover, these KO mice exhibited deficits in hippocampal long term potential (LTP), the most extensively studied form of long-lasting synaptic plasticity widely regarded as the cellular mechanism for learning and memory, which was accompanied by reduced NMDA/AMPA ratios (Blundell et al., 2010; Jedlicka et al., 2013). Together, these results suggest that NLGN1 is important in cognitive and repetitive behaviors characteristic of autism although the relationship between LTP, NMDA receptormediated synaptic transmission, and the observed behavioral deficits remains unclear. Other studies have examined the role of NLGN1 in a transgenic mouse model under a ubiquitous Thy1promoter to drive neuron-specific overexpression throughout the brain (Hines et al., 2008; Dahlhaus et al., 2010). These transgenic mice exhibited deficits in LTP and impairments in memory acquisition on the Morris water maze test, which further corroborates the importance of NLGN1 in synaptic plasticity and cognitive processes (Hines et al., 2008). Recent studies have shown that the conditional KO (CKO) of NLGN2 in the adult medial prefrontal cortex results in the gradual loss of inhibitory synapses (Liang et al., 2015). The authors deleted NLGN2 locally via bilateral stereotactic injection of AAVs expressing GFP tagged Cre-recombinanse. The mice exhibited impairments in anxietylike characteristics, fear memory, social interaction behaviors, and alterations in inhibitory synaptic properties (Durieux et al., 2015; Liang et al., 2015). The overexpression of NLGN2, which is exclusively expressed at inhibitory synapses, resulted in enlarged inhibitory synaptic contact size in the frontal cortex and an overall reduction in the ratio between excitatory and inhibitory synaptic activity (Hines et al., 2008). Furthermore, these animals displayed hyperactivity, increased stereotypic jumping, elevated anxiety-like behavior, and impaired social interactions but normal sociability (Hines et al., 2008). Together, these results confirm that NLGN2 plays an essential role at the inhibitory synapse and suggest that it may also contribute to ASD-like behaviors. Perhaps the best studied mouse model based on the NLGN genes that is relevant to autism are the NLGN3 knock-in (KI) mice harboring the R451C missense mutation (i.e., Arg451 is substituted with Cys451) because this mutation was shown to be linked to autistic patients. The NLGN3 R451C KI mice had a $90 \%$ decrease in NLGN3 protein levels in the forebrain based on immunoblotting analysis (Tabuchi et al., 2007). In addition, there was a slight decrease in the level of the NLGN1 isoform. The NLGN3 R451C KI mice exhibited increases in inhibitory synaptic transmission and deficits in social interactions but enhanced spatial learning and memory. Thus, the R451C substitution of NLGN3 acts as a gain-of-function mutation consistent with patients with ASD (Jamain et al., 2008). Other studies have demonstrated impaired tonic endocannabinoid signaling that is responsible for the altered inhibitory transmission (Foldy et al., 2013). Consistent with NLGN3 R451C KI, NLGN3KO mice (Varoqueaux et al., 2006) display behavioral phenotypes relevant to autism; including reduced ultrasonic vocalizations, a lack of social novelty preference, and a decrease in total brain volume (Radyushkin et al., 2009). Recent studies indicate that in both NLGN3 R451C KI and KO mice, there appear to be changes in synaptic mechanisms within the striatum that facilitate repetitive behaviors associated with this disease (Rothwell et al., 2014). NLGN4 KO mice were generated with a gene trap insertion $340 \mathrm{bp}$ downstream of the first exon of NLGN4 (first coding sequence) by BayGenomics. Since a small segment of the essential esterase domain remains, NLGN4 is unable to bind to NRXNs and therefore non-functional (Jamain et al., 2008). These KO mice had selective reductions in reciprocal social interaction 
and less ultrasonic vocalizations in males upon the presentation of anestrus female (Ey et al., 2012). Recent studies have also reported pronounced perturbations of $\gamma$-oscillatory network activity that is implicated in cognition (Hammer et al., 2015). To examine if there is a functional redundancy among the NLGN isoforms, Varoqueaux et al. (2006) generated NLGN1-3 triple $\mathrm{KO}(\mathrm{TKO})$ mice lacking their respective signal sequences and extracellular esterase-like domain to abolish NLGN gene expression completely. They chose to focus on NLGN1-3 due to the high expression levels in the brains of newborn mice. It is interesting to note that while NLGN3 is present at both excitatory and inhibitory synapses, NLGN1 and NLGN2 appear to be exclusively expressed at excitatory and inhibitory synapses respectively. These homozygous TKO mice had apparent irregular breathing movements resulting in respiratory failure and death shortly after birth (Varoqueaux et al., 2006). Furthermore, impaired glutamatergic and GABAergic synaptic transmission led to reduced excitatory drive and low spontaneous synaptic activity (Varoqueaux et al., 2006). Therefore, these results suggest that NLGN1-3 are critical for maintaining the excitatory and inhibitory balance for proper synaptic activity. In summary, the results from the mouse models based on altered NLGN genes are consistent with the notion that changes and mutations in the NLGN genes contribute to autistic phenotypes likely through altered synaptic properties, including abnormal excitatory/inhibitory balance, synaptic plasticity, and endocannabinoid signaling.

\section{SH3 and Multiple Ankyrin Repeat Domains (Shanks)}

The Shank family (Shank1-3) of genes code for post-synaptic scaffolding proteins with multiple protein-protein interaction domains (Naisbitt et al., 1999). These domains include a Src homology 3 domain (SH3), ankyrin repeats domain (ANK), post-synaptic density 95 PSD-95/disks large/zone occludens1 domain, a proline-rich region, a homer-binding region, a cortactin-binding region, and a sterile alpha motif (Naisbitt et al., 1999). The Shank proteins are localized to the postsynaptic density and are important in coordinating the assembly of signaling complexes at glutamatergic synapses (Bockers et al., 2001; Durand et al., 2007). Mutations in Shank3 have been strongly implicated in ASD compared to the other two Shank family genes, and therefore, various lines of Shank3-mutant mice have been generated to investigate the functional role of each of the domains and its contribution to the neuropathology of ASD. One of the first studies used the Cre/loxP system to disrupt the exons coding for the ANK of Shank3 thereby allowing regional-specific targeting of the gene (Bozdagi et al., 2010). Specifically, the loxP sites were inserted to flank the ANK and the floxed region was then excised by crossing it to CMV-Cre transgenic mice. The Shank3-deficient mice displayed reduced basal glutamatergic synaptic transmission and LTP along the Schaffer collateral pathway and impaired reciprocal social interactions including reduced social behavior reflected through conspecific sniffing and vocalizations (Bozdagi et al., 2010). Recent studies demonstrate that the homozygous deletion of the ANK result in a significant reduction in NMDA/AMPA ratio at the excitatory synapses onto striatal medium spiny neurons and impairments in LTP (Jaramillo et al., 2015). The haploinsufficiency of Shank3 or the loss of one functional copy of the Shank3 gene results in chromosome 22q13 deletion syndrome or Phelan-McDermid syndrome and autism (Phelan et al., 2001; Uchino and Waga, 2013). Studies have genetically targeted Shank $3 \alpha$, the longest Shank3 isoform that is responsible for encoding the ANK without affecting Shank3 $\beta$ and Shank3 $\gamma$ isoforms (Peca et al., 2011). Shank3 $\alpha$ KO mice were found to have modest ASD-like behavioral outcomes. Peca et al. (2011) also created a second mouse line that targeted another isoform, Shank3 $\beta$, through the deletion of the exons coding for the fragment containing the PSD-95/disks large/zonula occludens1 or PDZ domain. It is important to note that in this study, the Shank $3 \alpha$-and $\beta$ - isoforms were completely eliminated and the Shank $3 \gamma$ - isoform was only significantly reduced (Peca et al., 2011). These Shank $3 \alpha \beta$ KO mice were found to have normal gross anatomy but displayed anxiety-like behaviors and compulsive repetitive grooming behavior that resulted in self-inflicted skin lesions (Peca et al., 2011). However, individually, on tests of social interaction, Shank $3 \beta$ KO mice were less sociable, while Shank $3 \alpha \mathrm{KO}$ mice displayed mild impairments in social novelty recognition (Peca et al., 2011). In a recent study, Speed et al. (2015) knocked-in a single guanine nucleotide into exon 21 of the Shank3 gene, which mimics an autism associated insertion mutation and results in a frameshift causing a premature Shank3 protein. These mice displayed spatial learning deficits, impaired motor coordination, and altered novelty and sensory processing salient with the cardinal features of autism (Speed et al., 2015). Therefore the results from the Shank3 mice are consistent with the idea that deletions/mutations at the Shank3 gene are contributing factors for ASD through regulating synaptic function at excitatory synapses.

\section{INTELLECTUAL DISABILITY}

Intellectual disability is one of the most devastating neurodevelopmental disorders in children and young adults. ID involves impairments in general mental abilities that affect conceptual, social, and practical domains of everyday tasks. Children with ID often have IQ scores approximately two standard deviations below the population (Mandel and Chelly, 2004). This pervasive disorder manifests itself beginning at early development and comorbid with other neurological conditions including ASD, depression, and attention-deficit/hyperactivity disorder. The prevalence of ID has been gradually increasing in the last decade and said to affect 3\% of the population (Chelly and Mandel, 2001). Due to the severity and the social/economic effect of the disease, numerous attempts have been made to better understand the development and behavior in these children. However, the complexity of other symptoms including comorbid features renders it difficult to interpret the genetic and environmental factors involved in the pathophysiology of ID. ID is classified into two primary categories based on the clinical presentation, syndromic and non-syndromic ID, which 
allows different candidate genes to be tested for genotype and phenotype comparisons. Syndromic ID includes all patients present with one or multiple clinical features or comorbidities, whereas non-syndromic ID describes patients with ID as the sole clinical feature. In this section, we will discuss selected mouse models for both syndromic and non-syndromic ID and illustrate how genetically altered mice are used to study the etiology of ID.

\section{p21-Activated Kinases}

In the mammalian central nervous system, PAKs (p21-activated kinases) are a family of serine/threonine protein kinases that are activated by Rho-family small GTPases, such as RhoA, Rac, and Cdc42 (Field and Manser, 2012). The PAK family is divided into group I and II kinases based on the presence of an autoinhibitory domain (AID). Since group II PAKs lack an AID, binding by upstream Rho-family GTPases does not always lead to consistent activation of the kinase (Manser et al., 1995; Baskaran et al., 2012). Group I PAKs are involved in multiple cellular processes particularly actin regulation, cell proliferation, apoptosis, and gene expression and alterations in PAK1-3 are associated with tumor formation, inflammation, and cognitive dysfunction (Kumar et al., 2006; Zhao et al., 2006). Recent studies have demonstrated that $25-35 \%$ of ID have genetic associations with nonsense or missense mutations on the $\mathrm{X}$ chromosome, some of which result from loss of function in the PAK3 gene (Kelly and Chernoff, 2012). A number of mouse models have thus been generated based on the PAK genes to investigate the in vivo role of these genes and how their mutations contribute to ID (Allen et al., 1998; Boda et al., 2004; Dubos et al., 2012). Hayashi et al. (2004) generated a transgenic mouse model to inhibit the catalytic activity of group 1 PAKs in the postnatal forebrain. The dominant-negative PAK (dn-PAK) transgene, which consisted of an $\alpha$-CaMKII promoter, amino acids 74146 encoding the AID of PAK3, and SV40 intron/polyA, was used to create the mouse model (Hayashi et al., 2004). The dnPAK transgenic mice displayed decreased spine density and increased proportion of large synapses in cortical pyramidal neurons. Surprisingly, these mice showed enhanced AMPARand NMDAR-mediated synaptic transmission and LTP (Hayashi et al., 2004). Behaviorally, the dnPAK mice exhibited specific impairments in the consolidation and retention of hippocampaldependent memory in a fear conditioning paradigm. These data suggest that PAKs in general play a role in synaptic structure and plasticity and cognitive processes. PAK1 and PAK3 single $\mathrm{KO}$ mice were previously created by replacing a part of the coding and adjacent upstream/downstream intronic sequence by a pgk-neomycin resistant cassette to completely eliminate the entire kinase domain of PAK1 and 3 respectively (Meng et al., 2005; Asrar et al., 2009). PAK1 KO mice revealed normal brain anatomy but selective deficits in LTP at hippocampal CA1 synapses with changes in levels of actin binding protein, cofilin (Asrar et al., 2009). PAK3 KO mice resulted in no deficits in either cofilin activity or the actin cytoskeleton with mild impairments in late-phase LTP and learned taste aversion (Meng et al., 2005). In a recent study, Huang et al. (2011) investigated the role of PAKs by analyzing double knockout (DKO) mice lacking both PAK1 and PAK3 to eliminate functional redundancy. The DKO mice were generated by crossing previously characterized single PAK1 and PAK3 KO mice (Meng et al., 2005; Asrar et al., 2009). The DKO mice exhibited impaired postnatal brain growth, deficits in dendritic arborization and spine morphology, with alterations in synaptic transmission and plasticity (Huang et al., 2011). Furthermore, the DKO mice displayed a host of behavioral deficits consistent with ID-like symptoms including hyperactivity, increased anxiety, and learning and memory deficits. The alterations in spines were rescued by blocking cofilin activity suggesting cofilin-dependent actin regulation may mediate the effect of PAK1 and PAK3. Actin, the major cytoskeletal component in dendritic spines, is known to regulate a host of synaptic properties particularly post-synaptic receptor trafficking and spine morphology (Meng et al., 2004). Since the genetic deletions of either PAK1 or PAK3 in mice have only produced modest effects, PAK1 and PAK3 appear to have at least some overlapping functions in synaptic and cognitive regulation (Meng et al., 2005; Asrar et al., 2009; Huang et al., 2011). Further, analyses of these single and double $\mathrm{KO}$ mice will be needed to elucidate the in vivo roles and detailed mechanisms of PAKs. In addition, mouse models with specific PAK gene mutations relevant to ID will be required to translate animal studies to human conditions. Ultimately, these studies will help to reveal cellular and molecular mechanisms involved in the pathogenesis of non-syndromic $\mathrm{x}$-linked ID.

\section{Fragile X Syndrome}

Fragile $\mathrm{X}$ syndrome is the most commonly inherited form of ID and the most common cause of autism (O'Donnell and Warren, 2002; Hayashi et al., 2007; Pietropaolo and Subashi, 2014). FXS is a genetic diagnosis affecting 1 in 1250 males and 2500 females (Crawford et al., 2001). More specifically, FXS is a multi-organ disease with widespread effects leading to ID, macroorchidism in males, and premature ovarian insufficiency in females (Brennan et al., 2006; Ascano et al., 2012). FXS patients exhibit an increased incidence of seizures, anxiety, depression, and subtle motor impairments (Berry-Kravis et al., 2007; Basuta et al., 2011; Chonchaiya et al., 2012). This neurodevelopmental disorder is caused by the loss of the Fragile $\mathrm{X}$ mental retardation protein (FMRP) encoded by the Fragile X mental retardation 1 (FMR1) gene (Verkerk et al., 1991). Clinical studies reveal that patients with FXS have increased expansion and hypermethylation of trinucleotide (CGG) repeats within the promoter of FMR1 (Fu et al., 1991; Kremer et al., 1991a,b). FMRP is predominantly expressed within the cytoplasm of cells and have been implicated in translational processes including RNA interference and RNA subcellular localizations by facilitating nucleo-cytoplasmic shuttling (Devys et al., 1993; Eberhard and Grummt, 1996; Fridell et al., 1996). Human studies have revealed that FXS patients have abnormal development and morphological changes such as increased abundance of long, thin, and immature dendritic spines (Hinton et al., 1991; Irwin et al., 2001). The molecular mechanisms governing the spine and behavioral anomalies observed in FXS are not clear but analyses of FRMP mouse models based on the FMR1 gene 
have provided significant progress, which will be discussed below.

\section{Fragile X Mental Retardation Protein}

In order to examine the effects of the FMRP, the DutchBelgian Fragile-X Consortium engineered a mouse model in which the wild-type murine FMR1 gene was knocked out through introducing a neomycin cassette (Bakker et al., 1994; No authors, 1994). The FMR1KO mice displayed similar phenotypic characteristics seen in patients with FXS; including hyperactivity, increased anxiety and depressive-like states, cognitive deficits, and macroorchidism in male mice (Bregman et al., 1988; Bakker et al., 1994; No authors, 1994; Kooy et al., 1996; Yuhas et al., 2011). In a recent study, FMR1KO mice further showed reduced social discrimination between a familiar and novel mouse (Sorensen et al., 2015). However, FMR1KO mice lack FMRP expression in the entire animal. Thus to specifically investigate the spatial and temporal expression patterns of FMRP, the design of more novel and versatile KO models were needed. Mientjes et al. (2006) used the Cre/loxP system to disrupt the exons coding for FMR1 to achieve Purkinje cell-specific expression. The floxed region was then excised by crossing it to pcp-2/L7-Cre expressing mice to generate conditional FMR1KO (CKO) mice (Mientjes et al., 2006). These FMR1CKO mice revealed deficits in classical cerebellar-mediated delay eye-blink conditioning (Koekkoek et al., 2005). Amiri et al. (2014) used Nse-Cre (neuron-specific enolase promoter-driven Cre transgene) mice to drive loxP-specific deletion of FMR1 in subsets of neurons in the mouse cortex and hippocampus at 4 weeks of age. The FMR1CKO mice showed elongated spines and cell physiological abnormalities at the parallel fiber synapses that form on these spines (Amiri et al., 2014). Due to the similar sequence homology and tissue distribution, FXR2P, a homolog of the FMRP, has been suggested to compensate in part for the function of FMRP which may explain the mild phenotypes observed in FMR1KO mice (Kirkpatrick et al., 2001; Bontekoe et al., 2002; Mientjes et al., 2006). FXR2KO mice were created through inserting a neomycin resistant gene to study the function of FXR2P. Similar to FMR1KO mice, FXR2KO mice exhibited hyperactivity accompanied by mild disruptions on the rotarod test (Bontekoe et al., 2002; Spencer et al., 2006). However, FXR2KO mice exhibited less contextual conditioned fear, reduced prepulse inhibition, and learning deficits on the Morris water maze test, suggesting that FXR2 and FMR1 may play different roles in FXS phenotypes (Bontekoe et al., 2002). To examine if FXR2 and FMR1 have overlapping functions, other studies have created the FMR1/FXR2 double KO (DKO) mice through crossing individual FMR1KO and FXR2KO mice (Bontekoe et al., 2002). These DKO mice demonstrate increased anxiety, hyperactivity, reduced prepulse inhibition, and deficits in spatial and associative learning and memory suggesting a functional relationship between FXR2P and FMRP (Spencer et al., 2006). Together, these different methods of targeting FMRP and FXR proteins outline how these interactions can contribute to FXS phenotypes. However, further analyses are needed to elucidate the detailed cellular and molecular mechanisms involved in the pathogenesis of FXS.

\section{Williams- Beuren Syndrome}

Williams- Beuren syndrome (WS) is a neurodevelopmental disorder caused by the deletion of a 1.5-million-bp-segment on chromosome 7 (7q11.23; Pober, 2010). This microdeletion is caused by misalignment of chromosome 7 , a region spanning 28 genes flanked by highly homologous clusters of genes during meiosis that results in unequal homologous recombination and consequently deletion (Pober, 2010). To date, WS is a rare disorder that affects approximately 1 in 7500 births (Stromme et al., 2002; Sanders et al., 2011). Patients with WS exhibit a broad range of cognitive and systemic deficits. These include congenital heart disease, an ID profile with an unusual pattern of abilities (IQ of approximately 64 but are concrete in vocabulary and verbal short-term memory), and weaknesses in visuospatial construction and long-term memory (Mervis and John, 2010; Mervis and Velleman, 2011). Genetic association studies have implicated a variety of genes to contribute to the cognitive and behavioral profile of WS. However, only a few of these targets that reside in the commonly deleted hemizygous region have exhibited consistent cognitive and behavioral deficits of WS when translated to a mouse model. These include LIMK1 (Frangiskakis et al., 1996), CLIP2 (Hoogenraad et al., 2002), GTF2I (Merla et al., 2010), and GTF2IRD1 (Merla et al., 2010). Although, several genetic models have been produced and characterized for these genes, we will focus on LIMK1 KO mice that partially recapitulate the behavioral and cognitive profile of WS.

\section{Lim Domain Containing Kinase}

Lim domain containing kinase 1 (LIMK1) is a serine/threonine protein kinase and a potent regulator of actin dynamics via phosphorylating and thus inactivating the actindepolymerization factor (ADF)/cofilin (Arber et al., 1998; Yang et al., 1998; Sumi et al., 1999). In vitro studies have indicated that the Rho family small GTPases, Rac1 and Cdc42, bind and activate PAKs and ROCK protein kinases, which phosphorylate and activate LIMK1 (DesMarais et al., 2005; Jia et al., 2009; Huang et al., 2011). The activated LIMK1 can directly phosphorylate and inactivate cofilin, which promotes actin polymerization (DesMarais et al., 2005; Jia et al., 2009; Huang et al., 2011). Human genetic studies reveal that WS patients with smallest microdeletions containing the LIMK1 gene (Tassabehji et al., 1996) show some key WS phenotypes (i.e., visuospatial deficit), suggesting that LIMK1 may be a key factor in WS pathology. To test this hypothesis, LIMK1KO mice were generated replacing a part of the second LIM and PDZ domains with a pgk-neomycin resistant cassette, to completely eliminate the kinase domain (Meng et al., 2002). These mice had normal expression of other proteins including LIMK2, PAKs, ROCK2, and cofilin, but reduced cofilin phosphorylation and altered actin networks and spine morphology. Behaviorally, the LIMK1KO mice displayed deficits in locomotion, fear responses, and visuospatial cognition (Meng et al., 2002). Recent studies have also identified that LIMK1KO were particularly impaired in long-lasting LTP (specifically late-phase LTP) and the formation of long-term memory (Todorovski et al., 2015). In addition, LIMK1KO mice were found to have a reduction in active (phosphorylated) CREB and increasing CREB activity rescued the long-term memory 
deficits in these mice suggesting that impaired CREB signaling may be responsible for late-LTP and long-term memory deficits. Taken together, these studies indicate that the deletion of LIMK1 is sufficient to cause synaptic dysfunction and impaired long-term memory that may be relevant to WS. Therefore, LIMK1 is likely a key factor in WS pathology. Furthermore, these studies also suggest that LIMK1 regulates synaptic plasticity and behavior via two distinct mechanisms; cofilin-mediated actin reorganization and CREB-mediated gene expression. Ultimately, these studies may provide insight into the neural circuitry and molecular targets for treating and preventing WS.

\section{SCHIZOPHRENIA}

Schizophrenia is a chronic neuropsychiatric disorder characterized by positive and negative symptoms, including delusions, hallucinations, disorganized speech, catatonic behavior, diminished emotional expression, and impaired cognition (Abazyan and Pletnikov, 2014). Given the severity and heterogeneity of these core symptoms, schizophrenia is deemed to be one of the most debilitating diseases by the World Health Organization, affecting approximately 1\% of the entire population. The onset of schizophrenia is in post-adolescence (16-25 years), but the course of the illness and presentation of core symptoms can persist into adulthood (40-60 years). Although genetic and environmental factors contribute to the etiology of schizophrenia, no specific biomarkers have been identified for this multifactorial disorder. In a recent study Ayalew et al. (2012) used a translational convergent functional genomics approach to identify and prioritize genes involved in schizophrenia. Through, gene-level integration of genome-wide association data combined with gene expression studies in humans and animal models, they identified top candidate genes including: DISC1, NRG1, RELN, and many others (Ayalew et al., 2012). Their findings shed light on novel promising targets for future pharmacological treatments for patients with schizophrenia. In this section, we will discuss two well-characterized genetic mouse models of schizophrenia that have recreated structural and behavioral dysfunctions associated with the disease. In the end of this section, we will briefly discuss alternate models that have been used to examine the effects of dopamine and glutamate neurotransmission in schizophrenia.

\section{Disrupted-in-Schizophrenia 1}

Disrupted-in-Schizophrenia 1 (DISC1) is a scaffolding protein with numerous binding partners that facilitate the formation of protein complexes (Morris et al., 2003; Camargo et al., 2007). In humans, DISC1 is 854 amino acids long consisting of a $\mathrm{N}$-terminal globular head domain and a long helical C-terminal coiled tail domain (Chubb et al., 2008; Soares et al., 2011). DISC1 is expressed systemically in the heart, liver, kidney, and thymus, but highly enriched in the cerebral cortex, hippocampus, hypothalamus, amygdala, cerebellum, and olfactory bulbs in the brain (Ma et al., 2002; Austin et al., 2004; Brandon et al., 2009). The DISC1 gene was first identified as a risk factor for mental disorders including schizophrenia, schizoaffective disorder, recurrent major depression, and adolescent conduct and emotional disorder, in a Scottish pedigree that displayed a translocation between chromosomes 1 and 11 (q42;q14.3; St Clair et al., 1990). Since then, other studies have confirmed that the translocation $t(1 ; 11)$ disrupts the DISC1 gene in several populations, that are also susceptible to similar psychiatric illnesses (Sachs et al., 2005; Chubb et al., 2008). The first DISC1 mouse model was engineered based on a spontaneous 25-bp deletion in exon 6 of the DISC1 gene in a 129S6 strain that abolished the production of the full-length DISC1 protein (Koike et al., 2006). The DISC1-deficient mice exhibited cognitive dysfunction specifically in spatial working memory (Koike et al., 2006). In recent studies on the same DISC1-deficient mice, Kvajo et al. (2011), found widespread and cumulative cytoarchitectural alterations in the dentate gyrus during neonatal and adult neurogenesis. In particular, they noticed errors in axonal targeting and impaired dendritic growth that are accompanied by changes in short-term plasticity at mossy fiber/CA3 synapses (Kvajo et al., 2011). Furthermore, Juan et al. (2014) revealed subtle working memory impairments were mediated by decreased neuronal excitability and morphological alterations in layer II/III pyramidal neurons in the medial prefrontal cortex in the same DISC1-deficient mice. These studies suggest that the DISC1 gene from the $129 \mathrm{~S} 6 / \mathrm{SvEv}$ strain is important for neuronal connectivity, short-term synaptic dynamics and working memory. Other models have been established based on mutations in the mouse DISC1 gene via $N$-nitroso- $N$-ethylurea (ENU) mutagenesis, which induces point mutations at a high locus-specific rate (Coghill et al., 2002). Clapcote et al. (2007), identified and analyzed two independently derived ENU-induced missense mutations in the 955-bp exon 2 of mouse DISC1, known as Q31L and L100P. They chose to focus on exon 2 due to the fact that it is the longest, present in all known splice isoforms, and encodes most of the head domain of the DISC1 protein (Millar et al., 2005; Clapcote et al., 2007). The Q31L mice displayed depressive-like behavior or learned helplessness in the forced swim test (FST), reduced sociability, and low sucrose consumption indicative of anhedonia (Clapcote et al., 2007). The L100P mice exhibited schizophrenic-like behavior with profound deficits in prepulse inhibition and latent inhibition, common methods to quantify information-processing deficits. These L100P mice also had greater horizontal locomotion and decreased working memory performance on the T-maze task (Clapcote et al., 2007). The deficits observed in L100P mice could be reversed by pharmacological or genetic inactivation of glycogen synthase kinase 3 (GSK-3 $\alpha$ and GSK-3 $\beta$; Clapcote et al., 2007). Similarly, the Q31L deficits in prepulse inhibition and FST could be rescued following a GSK-3 blocker, TDZD-8, suggesting a role for GSK-3 in mediating the effects of DISC1 (Lipina et al., 2012). Recent studies have shown that the Q31L mice have fewer proliferating cells, whereas the L100P mice have differences in the generation, placement, and maturation of newly generated neurons in the adult hippocampus (Chandran et al., 2014). Despite these differences, both models share structural and functional brain abnormalities, particularly reductions in overall brain volume due to tissue contraction in the neocortex, thalamus, and cerebellum. Thus, both the Q31L and L100P 
mice exhibit impairments that are consistent with the positive, negative, and cognitive symptoms of schizophrenia. In recent studies, Lee et al. (2013) discovered altered interneuron density and location in the L100P mice due to selective impairments in calbindin- and parvalbumin-expressing interneurons in the cortex and hippocampus, and consequently decreased GAD67/PV co-localization in the neocortex, suggesting a role of inhibitory transmission in schizophrenia. Lastly, there have also been other transgenic models that result in the expression of mutant DISC1 in a spatial-temporal manner. Hikida et al. (2007) have exogenously expressed dominant-negative truncated DISC1 (DN-DISC1) under the regulation of an $\alpha$-CaMKII promoter that is restricted in the olfactory bulb, frontal cortex, hippocampus, and basal ganglia. In this particular model, DN-DISC1 did not affect the expression level of the endogenous DISC1 gene (Hikida et al., 2007). Similar to patients with schizophrenia, the DNDISC1 mice displayed enlarged lateral ventricles contributing to asymmetrical brain anatomy, interneuron deficits resulting in cortical synchrony, and impairments in prepulse inhibition, FST, and spontaneous activity. Therefore, analysis of the DISC1 mouse models has contributed significantly to and will continue to provide new insights to our understanding of the in vivo function of the DISC1 gene and how its alterations result in schizophrenia.

\section{Neuregulin-1}

The family of neuregulins, also known as NDF, heregulin, GCF, and ARIA (NRG1-4), are epidermal growth factors (EGFs) that activate ErbB receptor tyrosine kinases, and play diverse roles in normal developmental processes, plasticity, and oncogenesis (Burden and Yarden, 1997; Harrison and Law, 2006; Britsch, 2007). Neuregulin-1 (NRG1), the best characterized amongst the four neuregulins, was discovered in 1992 and shown to have diverse functions in the heart, breast, and nervous system (Holmes et al., 1992; Harrison and Law, 2006). In the brain, NRG1 modulates neuronal migration, glial development and differentiation, and synaptic transmission and plasticity (Harrison and Law, 2006). In 2002, NRG1 was identified as a candidate gene for schizophrenia in a genome-wide linkage scan conducted by Stefansson et al. (2002). In this study, the NRG1 gene was mapped to the chromosome 8p locus (8p11p21), a region linked to schizophrenia. Therefore, numerous mouse models have been generated to examine the functional consequences of targeting NRG1 and its receptor, ErbB. To target the EGF-like domain, exon 6 of the NRG1 gene was fused to $\beta$-galactosidase (NRG1-LacZ), which resulted in the partial deletion of the EGF-like domain of all three isoforms of NRG1 (Meyer and Birchmeier, 1995). Also, a second vector was used that targeted exons 7-9, which encode parts of the EGF domain (carboxy-terminus) of NGR1, was replaced by a neomycin resistance gene (Meyer and Birchmeier, 1995). The matings between heterozygous mice carrying either mutation produced no homozygous mutant offspring, indicating that the complete deletion of NRG1 and its receptor, ErbB, are lethal during embryogenesis due to heart malformations and defects in Schwann cells and cranial glia development (Meyer and Birchmeier, 1995). Therefore, NRG1 and its ErbB receptor are indispensable during development. In subsequent studies, the NRG1 heterozygous mice were therefore used and found to exhibit significant behavioral alterations such as hyperactivity in the open field test, improved rotorod performance, and enhanced spontaneous alternation ability in T or Y-maze tests (Gerlai et al., 2000; Stefansson et al., 2002; O’Tuathaigh et al., 2007). Other studies have shown that hyperactivity and increased locomotion in NRG1 heterozygous mice can be reversed with clozapine (an antipsychotic to treat schizophrenia) and environmental enrichment (Karl et al., 2007; Duffy et al., 2008). Therefore, the targeted deletion of NRG1 provides novel insights into the role of NRG1 and supports that it may contribute to schizophrenia. Several studies have also examined the effects of increased NRG1 expression in transgenic mouse models. Kato et al. (2010) constructed a transgenic vector that contained the promoter of a house keeping gene, elongation factor $1 \alpha$ $(\mathrm{EF}-1 \alpha)$ and GFP-tagged NRG1 cDNA that drives ubiquitous expression in the whole brain. They confirmed through Western blot and real-time quantitative reverse transcription that the overexpression of NRG1 was 4.3-fold higher than wild-type littermates (Kato et al., 2010). Behaviorally, the transgenic mice had elevated locomotor activity, decreased context-dependent fear conditioning, and impaired social interaction in an isolationinduced resident-intruder test (Kato et al., 2010). Moreover, the mice had an increased expression of GABAergic paravalbumin and myelination markers in the frontal cortex, suggesting a role for NRG1 in inhibitory transmission. Therefore, the mouse models based on NRG1 presented in this section help to identify the behavioral and mechanistic processes that may be relevant to the pathophysiology of schizophrenia.

Although, we have discussed two well-characterized genetic models used for studying the pathophysiological mechanisms of schizophrenia, other studies exist that attribute the pathological mechanisms of schizophrenia to dopamine (DA) and glutamatergic neurotransmission dysfunction. The DA hypothesis of schizophrenia proposes that hyperactive DA transmission in the striatum contributes to positive symptoms of schizophrenia while cognitive functions and negative symptoms may result from hypoactive DA neurotransmission in the prefrontal cortex (Carlsson and Lindqvist, 1963; Davis et al., 1991; Howes and Kapur, 2009). Animal models have thus been created to evaluate the roles of $\mathrm{D} 2$ receptors in neurotransmission via inducible overexpression in the striatum alone (Kellendonk et al., 2006). The D2 transgenic mice exhibited selective cognitive impairments in working memory tasks that may be relevant to schizophrenia (Kellendonk et al., 2006). In the second hypothesis, glutamate receptors specifically NMDA receptor hypofunction have been associated with the negative symptoms and cognitive dysfunction similar to schizophrenia (Javitt and Zukin, 1991; Coyle, 2006; Javitt, 2007). Studies have found that hypomorphic NR1 mice with approximately $4 \%$ expression of NR1 (via inserting a neomycin resistance gene into intron 20) exhibit complex phenotypes including hyperactivity and decreased social interactions (Mohn et al., 1999; Duncan et al., 2002). Therefore, analysis of these models will be useful to determine the role and underlying mechanisms of DA and glutamate transmission in the pathogenic processes of schizophrenia. 


\section{ALZHEIMER'S DISEASE}

Alzheimer's disease is a debilitating age-associated neurodegenerative disorder, affecting more than 35 million people worldwide (Hall and Roberson, 2012). This neurocognitive disorder results in a decline of intellectual function usually beginning with impaired language usage or communication and ultimately, interferes with one's ability to function independently (Janus and Borchelt, 2014). Therefore, as one of the most devastating neurodegenerative disorders, potential biomarkers have been developed via brain imaging such as MRI and PET scans, genetic, and biochemical studies. AD has a well-defined neuropathological profile including the presence of extracellular amyloid plaques, accretion of intracellular neurofibrillary tangles (NFTs), neuronal damage, and death in selected brain regions (Arnold et al., 1991; Vigo-Pelfrey et al., 1993; Braak and Braak, 1994; Petersen et al., 1999; Naslund et al., 2000). Genetic linkage and positional cloning strategies have identified various genes associated with AD. These include: amyloid precursor protein, presenilin 1 and 2, $\alpha-2$ macroglobulin, low-density lipoprotein receptor-related protein and others (Goate et al., 1991; LevyLahad et al., 1995; Sherrington et al., 1995; Sperling et al., 2011). In this section, we will discuss three genetic models targeting amyloid- $\beta$-precursor protein, presenilin 1 and 2 , and tau that are involved in producing the $\mathrm{AD}$ phenotype.

\section{Amyloid- $\beta$-Precursor Protein}

Amyloid- $\beta$-precursor protein (APP) is a type I (single-pass) transmembrane protein with a large amino-terminal extracellular domain (O'Brien and Wong, 2011; Hall and Roberson, 2012). Gene mutations in APP alter the production and deposition of the amyloid-beta peptide $(A \beta)$, which hasten the production of extracellular amyloid plaques (Goate et al., 1991). The A $\beta$ peptides (36-43 amino acids long) are generated from APP by $\beta$ - and $\gamma$-secretase (Lewis et al., 2001). Alternative splicing of the APP transcript generates eight isoforms, but only one (695 amino acid form) is predominantly expressed in the CNS (Bayer et al., 1999). The first genetic model to target APP used the PDGF- $\beta$ promoter to drive expression of APP717 cDNA gene encoding a variant mutation where valine at residue 717 is substituted by phenylalanine (V717F) that leads to overexpressing 40 copies of the transgene (Games et al., 1995). This missense mutation in APP is tightly linked to autosomal dominant forms of AD (Games et al., 1995). These and other transgenic mice [i.e., the ones using similar Thy1-APP (V717F)] displayed a ten-fold elevation of APP protein and resulted in deficits in reference memory on the radial arm maze and spatial memory on the Morris water maze test, and an accumulation of amyloid in the brain between 6 and 7 months (Games et al., 1995; Dodart et al., 1999; Moechars et al., 1999). Therefore, overexpression of this mutant APP is sufficient for the formation of amyloid plaques in mice. However, other anatomical anomalies and their mechanisms were not investigated including dystrophic neurites, the formation of NFTs, and reduced synaptic density and function. Perhaps one of the best characterized animal studies of $\mathrm{AD}$ is the Tg2576 transgenic mouse model, which overexpresses a mutant APP containing Swedish FAD (K670N/M67L) double mutations at the two $\beta$-secretase cleavage sites responsible for $\mathrm{A} \beta$ production (Hsiao, 1998). Compared to the previous model, the Tg2576 mice have moderate levels of APP overexpression (5-6 fold of the endogenous level; Hsiao, 1998). The mice had a slow accumulation of amyloid in the neocortex and hippocampus around 12 months (SturchlerPierrat et al., 1997; Kawarabayashi et al., 2001) and impaired spatial reference and contextual memory (Comery et al., 2005). Others have engineered transgenic mice harboring the Swedish and London FAD mutations, revealing that these double mutants have a sevenfold overexpression of APP with typical A $\beta$ plaques at the age of 6 months and 14-25\% neuronal loss between 14 and 18 months (Calhoun et al., 1998). Behaviorally, these mice showed a broad range of abnormalities that included changes in limb and stereotypic movements, deficits in learning and memory, and electrophysiological impairments in basal synaptic transmission (Roder et al., 2003; Comery et al., 2005). More recent studies have used a modified version of APP where the $A \beta$ peptide-coding domain of the mouse cDNA was humanized (Borchelt et al., 1996). In these mice, APP was expressed three-fold higher than the endogenous APP and were found to develop amyloid plaques at old ages (24-26 months) accompanied by various deficits in cognitive performance (Borchelt et al., 1996; Savonenko et al., 2003). Recent studies have shown that these mice with the overexpression of human APP demonstrate reductions in synapse-associated proteins including PSD95, AMPA and NMDA receptor subunits, and neuronal maker, MAP2, indicating signs of neurodegeneration in the hippocampus (Simon et al., 2009). Therefore, studies of mutant APP transgenic mouse models have indicated that abnormal expression of APP plays a critical role in AD pathology.

\section{Presenilin}

More than 150 familial mutations in presenilin 1 and presenilin 2 (PS1 and PS2) have been identified in AD (De Strooper, 2007). PSs encode the catalytic subunit of $\gamma$-secretase that cleaves APP to form A $\beta$ of varying lengths (De Strooper, 2007). $\mathrm{AD}$-associated PS mutations have been shown to increase the two most common isoforms of $\mathrm{A} \beta, \mathrm{A} \beta 42$ and $\mathrm{A} \beta 40$, both of which are known to be responsible for the rate of amyloid deposition (Borchelt et al., 1996; Scheuner et al., 1996). PSs are also known to be involved in cell adhesion, calcium homeostasis, transport, trafficking/localization, and apoptosis (Hall and Roberson, 2012). To target PS1, several transgenic mice expressing different forms of the human mutated PS1 genes were created, to explore whether mutations in PSs cause cells to secrete a greater amount of amyloidogenic $A \beta$ peptides (Elder et al., 2010). The transgenic mice expressing mutant human PS1 [lines $\operatorname{Tg}(\mathrm{M} 146 \mathrm{~L}) 1, \operatorname{Tg}(\mathrm{M} 146 \mathrm{~L}) 76, \operatorname{Tg}(\mathrm{L} 286 \mathrm{~V}) 198$ ] showed significant overproduction of $\mathrm{A} \beta 42$ and no cognitive deficits in the Morris water maze test at 6 and 9 months of age (Janus et al., 2000). Only mutant PS1 co-expression with a mutant APP (Tg2576) showed early amyloid plaque deposition, neuron loss in the cerebral cortex, and cognitive dysfunction (Arendash et al., 2001; Lok et al., 2013). Taken together, these studies suggest that the full phenotypic expression of mutant PS1 alleles may require the co-expression of other $\mathrm{AD}$-associated genes. PS1 conditional knockout (CKO) mice 
were generated by crossing floxed PS1 mice with transgenic mice expressing Cre recombinase under a $\alpha$ CaMKII promoter so that PS1 was selectively inactivated in excitatory neurons in the postnatal forebrain ( $\mathrm{Yu}$ et al., 2001). The CKO mice showed normal basal synaptic transmission and plasticity, but exhibited mild deficits in spatial learning and memory. Other studies have found that the conditional inactivation of PS1 in APP transgenic mice prevented the accumulation of $A \beta$ peptides, the formation of amyloid plaques, and inflammatory responses but failed to ameliorate the contextual memory and synaptic deficits associated with APP transgenic mice (Saura et al., 2005). Conditional PS1 and PS2 double knockout mice (PS CDKO) revealed cortical shrinkage, hippocampal atrophy, and elevated levels of tau hyperphosphorylation that was accompanied by behavioral deficits in hippocampal-dependent learning and memory (Feng et al., 2004; Saura et al., 2005). Therefore, these results define essential roles of PSs in synaptic plasticity, learning and memory, and neuronal survival in the adult cerebral cortex.

\section{Tau}

The genes discussed above focused on recapitulating the $A \beta$ pathology in the formation of extracellular plaques in AD. However, $\mathrm{AD}$ also involves the development of intracellular NFTs mainly comprised of hyperphosphorylated forms of the microtubule-associated protein, tau (Lee et al., 2001). Studies have revealed over 30 mutations in the microtubule-associated protein, tau, in $\mathrm{AD}$ patients; ranging from missense, deletion, and silent mutations in the coding region, and intronic mutations, influencing the alternative splicing of tau or its protein level (Clark et al., 1998; Hutton et al., 1998; Goedert, 2005). The first tau KO mice were generated by replacing the signals for the start of translation of tau protein with a pgk-neomycin resistant cassette so that only short fragments incapable of binding to microtubule were produced (Harada et al., 1994). In later studies, these tau KO mice exhibited motor deficits and muscle weakness (Ikegami et al., 2000). Dawson et al. (2001) have also generated tau KO mice, on a BL/6/129sv mixed strain, and showed similar locomotor deficits in balance beam tests, but in this latter model, tau KO mice expressed significant cognitive deficits at 12 months. Furthermore, the authors were able to show that primary hippocampal neurons from the tau-deficient mice had delayed maturation in their axonal and neuritic extensions (Dawson et al., 2001). These results suggest that the genetic background of the tau-deficient mice may result in discrepancies on the deleterious effects of axonogenesis. Studies have shown that the ablation of tau ameliorates AD-related synaptic, network, and behavioral abnormalities in transgenic mice expressing human APP (Morris et al., 2015). Transgenic mice expressing human tau containing the P301L mutation (JNPL3) linked to frontotemporal dementia and Parkinsonism have been produced under the mouse prion promoter (Lewis et al., 2000). These mice were found to show moderate early behavioral deficits in escape extension during tail elevation and spontaneous back paw clenching (Lewis et al., 2000). In addition, these mice developed a progressive motor abnormality due to the loss of lower motor neurons (Lewis et al., 2000). In a later study, when the JNPL3 mice were crossed with the Tg2576 mice, there was an increase in the formation of filamentous tau inclusions and plaques in the forebrain regions compared to JNPL3 mice (Lewis et al., 2001). Behaviorally, these double transgenic mice developed motor disturbances associated with spinal cord and neuromuscular pathology. More recent findings have proposed that post-translational modifications such as acetylation and ubiquitination of endogenous tau, that is not bound to microtubules and is free to interact with diverse molecules in different neuronal compartments, mediates $\mathrm{A} \beta$-induced neuronal impairments (Morris et al., 2015). To study the neuropathological correlates of $\mathrm{AD}$, the interaction between $\mathrm{A} \beta$ and tau and their effect on synaptic function was examined in a triple transgenic mouse model (Oddo et al., 2003). Rather than crossing three independent lines of mice, Oddo et al. (2003) co-microinjected human tau (P301L) and Swedish FAD APP mutation (both under the control of a Thy1.2 neuron-specific regulatory element) into single-cell embryos from homozygous PS1(M146V) KI mice. They successfully found five of the six founder lines harbor all three mutations and in two lines the transgenes appeared to cointegrate at the same genetic locus (Oddo et al., 2003). The tight linkage coupled to the PS1 knockin site allowed the mice to breed as a "single" transgenic line (Oddo et al., 2003). The mice exhibited synaptic deficits (LTP) that were manifested in an age-dependent manner, followed by plaques at 3 months of age and NFTs by 12 months in the cerebral cortex, hippocampus, and amygdala (Oddo et al., 2003). These results are consistent with the amyloid cascade hypothesis. Ultimately, this triple Tg-AD mouse along with other $\mathrm{AD}$ models described above will provide valuable tools to evaluate the interaction and pathogenic mechanisms of various $\mathrm{AD}$ genes. Other models such as those based on Apolipoprotein E (ApoE) gene are also important to assess the involvement of glial cells in AD pathology, but will not be discussed here.

\section{PARKINSON'S DISEASE}

Age-related neurodegenerative diseases also include PD, which is becoming increasingly prevalent in our society. It is estimated that 10 million people worldwide are affected by PD (Hirtz et al., 2007). According to DSM-V, PD is a progressive neurodegenerative disorder clinically characterized by the cardinal symptoms of resting tremor, bradykinesia or the slowness of movement, cogwheel rigidity, and postural instability (Jankovic, 2008). Non-motor symptoms such as the presence of Lewy bodies and neurites that consist of aggregated forms of the 140 amino acid protein $\alpha$-synuclein were also found in postmortem brain studies and therefore considered to be one of the histological hallmarks of PD (Fearnley and Lees, 1991; Spillantini et al., 1998; Braak et al., 2003). As the second most common neurodegenerative disorder following $\mathrm{AD}, \mathrm{PD}$ also attracts a great deal of clinical and basic research. PD is characterized by the loss of dopaminergic cells in the substantia nigra that project to the striatum leading to nigrostriatal degeneration and motor symptoms (Forno, 1996), but the mechanisms underlying this cell loss remain unclear. Genetic models based on gene mutations linked to the monogenic form of familial PD have been essential tools for the mechanistic and treatment studies. In this section, 
we will discuss three different mouse PD models that have been used in the attempt to evaluate possible neuroprotective treatments and biomarkers for early diagnosis and disease-state identification. It is important to note that none of the current models have been able to precisely replicate all motor and non-motor symptoms, as well as Lewy body formation and nigrostriatal degeneration in an age-related progressive manner.

\section{$\alpha$-Synuclein}

Alterations in $\alpha$-synuclein (encoded by the SNCA gene) cause a rare form of autosomal dominant PD. Mutations in $\alpha$-synuclein is known to be the most common risk factor for idiopathic and familial PD (Pankratz et al., 2009; Satake et al., 2009). PD-related point mutations (such as A30P and $\mathrm{A} 53 \mathrm{~T})$, rare triplications, and duplications in the SNCA gene have been identified in human familial PD (Polymeropoulos et al., 1997; Ahn et al., 2008; Gasser, 2009). Therefore, various wild-type or mutant $\alpha$-synuclein transgenic mice have been developed to examine the consequences of overexpression of the SNCA gene under different promoters. Specifically, mice overexpressing human wild-type $\alpha$-synuclein under the platelet-derived growth factor- $\beta$ (PDGF- $\beta$ ) promoter (Line D) exhibited intraneuronal $\alpha$-synuclein aggregates in the neocortex, hippocampus, and olfactory bulb (Masliah et al., 2000). Furthermore, these mice had lower striatal levels of tyrosine hydroxylase (required for the synthesis of dopamine) enzymatic activity associated with the degeneration of nigrostriatal dopaminergic neurons (Masliah et al., 2000). Behaviorally, the mice displayed rotarod and spatial memory deficits. Thus, intraneuronal accumulation of $\alpha$-synuclein appears to be required for dopaminergic and behavioral deficits to become detectable (Masliah et al., 2000; Masliah and Hansen, 2012). Another model was generated that overexpressed mutant $\alpha$-synuclein under the Thyl promoter, which had a more widespread expression of $\alpha$-synuclein in neurons of the thalamus, basal ganglia, substantia nigra, and brainstem (Rockenstein et al., 2002). In this model, the human A53T mutation in $\alpha$-synuclein was introduced into the transgene (van der Putten et al., 2000; Rockenstein et al., 2002). These A53T transgenic mice showed late-onset pathological changes that include axonal degeneration in long white matter tracts of the spinal cord, the breakdown of myelin sheaths, and the degeneration of neuromuscular junctions with a loss of integrity of the presynaptic neurofilament network (van der Putten et al., 2000; Rieker et al., 2011). In an another study, Plaas et al. (2008), generated a mouse model with a subtle point mutation in $\alpha$-synuclein that replaced alanine with proline at position $30(\mathrm{~A} 30 \mathrm{P})$. The A30P mice exhibited an age-dependent decline in motor ability on the beam walk test and in mean stride length from all paws (Plaas et al., 2008). Furthermore, the SNCA A30P mice had deficiencies in vmat2, a vesicular transporter that regulates dopamine availability, which indicates that the motor defects may be due to a decreased content of dopamine in the striatum. Double transgenic mice harboring the A30P/A53T mutations displayed progressive decline with age in locomotor activity and stereological counts of tyrosine hydroxylase-positive neurons
(Thiruchelvam et al., 2004). In addition to overexpression studies, others have also engineered $\alpha$-synuclein $\mathrm{KO}$ mice. The $\mathrm{KO}$ mice were generated by using a floxed neomycin cassette to disrupt the SNCA gene and subsequently crossed with C57BL/6NTacGt(ROSA)26Sortm16(cre)Arte mice (Chandra et al., 2004). These KO mice had normal ultrasynaptic structure and survival rates but displayed decreased striatal dopamine levels (20\%), elevated lactate concentrations, and reduced rearing (Chandra et al., 2004; Drolet et al., 2004). These findings suggest that $\alpha$-synuclein may play a role in the maintenance of presynaptic vesicular function. Chandra et al. (2005) show that transgenic expression of $\alpha$-synuclein ameliorates the lethality and rapidly progressive neurodegeneration caused by the deletion of cysteine-string protein- $\alpha(\operatorname{CSP} \alpha)$, a synaptic vesicle protein essential for neuronal survival, in mice. The expression of transgenic $\alpha$-synuclein improved SNARE complex assembly, which suggests that $\alpha$-synuclein acts in conjunction with $\operatorname{CSP} \alpha$ to play an important role in protecting presynaptic terminals against neurodegeneration. Triple $\alpha \beta \gamma$-synuclein $\mathrm{KO}$ mice that lack all murine synucleins (generated through breeding previously characterized $\alpha \beta$-synuclein $\mathrm{KO}$ mice with $\gamma$-synuclein KO mice) present age-dependent alterations in synaptic structure and transmission, neuronal dysfunction, diminished survival, and late-onset phenotypes including retinal dysfunction (Burre et al., 2010; Greten-Harrison et al., 2010). Therefore, mouse models of altered $\alpha$-synuclein expression have increased our understanding of the role of $\alpha$-synuclein in PD related processes.

\section{Leucine-Rick Repeat Kinase 2}

Missense mutations in the leucine-rich repeat kinase (LRRK2) gene have been identified as causes of autosomal dominant PD with characteristics similar to the sporadic disease forms (Singleton, 2005; Cookson and van der Brug, 2008). LRKK2 is a 2527- amino acid protein consisting of several functional domains, including a leucine-rich repeat domain, a Ras-like small GTPases domain, and a kinase domain with sequence homology to MAP kinase (Tong and Shen, 2009). KO models have been generated for LRRK2 by flanking the first loxP site at intron 1 followed by, a neomycin expression cassette, and the second loxP at intron 2 of the LRRK2 gene (Parisiadou et al., 2009). These KO mice, resulting from crossing the floxed mice with EIIa-Cre-transgenic mice, were viable to adulthood and did not show any major abnormalities, suggesting that LRRK2 may not play a major role in the development and survival of dopaminergic neurons (Andres-Mateos et al., 2009; Parisiadou et al., 2009; Li et al., 2011). Recent studies have shown that the LRRK2 KO mice show increased protein kinase A- mediated phosphorylation of cofilin and glutamate receptor 1 (GluA1) and impaired synaptic transmission in the striatum (Parisiadou et al., 2014). Associations of LRRK2 have been found with microtubule dynamics, in particular the increased levels of soluble $\beta$-tubulin in LRRK2 KO mice (Gillardon, 2009). To date, there is no genetic support for the causal involvement of LRRK1, the closest paralog of LRRK2, in PD. Although, LRRK1 and LRRK2 share a high sequence homology in the brain, they function independently through interactions with different 
cellular proteins (Reyniers et al., 2014). LRRK1/LRRK2 double KO mice are available through Jackson Laboratories, but have not been characterized. Initial linkage studies have identified various LRRK2 missense mutations including G2019S and R1441G in patients with PD (Chen et al., 2012; Herzig et al., 2012). LRRK2 overexpression mouse models were created that bear the inducible G2019S mutation at the conserved $\mathrm{Mg}^{2+}$ binding motif within the kinase domain and resulted in consistently enhanced LRRK2 acitivty (Gilks et al., 2005; Nichols et al., 2005; West et al., 2005; Lin et al., 2009). This familial PD-related mutation caused impairments in dopaminergic neurotransmission that was linked to modified localization and phosphorylation of the microtubule-binding protein tau and consequences in motor function (Li et al., 2010; Melrose et al., 2010; Winner et al., 2011). Mice harboring the R $1441 G$ mutation demonstrate a strong behavioral phenotype and altered dopamine release recapitulating the cardinal features of $\mathrm{PD}$ ( $\mathrm{Li}$ et al., 2009). In particular these mice showed reduced rearing by 12 months that could be rescued by L-DOPA suggesting that the behaviors are dependent on dopamine. In a more recent study, R1441G KI mice showed perturbed dopamine homeostasis resulting in presynaptic dysfunction and locomotor deficits (Liu et al., 2014). Thus, LRRK2 mouse models have been shown to be a useful tool to understand the role of dopaminergic dysfunction in PD.

\section{Parkin, Phosphatase and Tensin Homolog (PTEN)-Induced Putative Kinase-1 and DJ-1}

Other studies indicate that autosomal recessive forms of familial $\mathrm{PD}$ are due to gene mutations in parkin, PTEN-induced putative kinase 1 (PINK1), and DJ-1 (Bonifati et al., 2003b). Parkin is an ubiquitin E3 ligase that is important in adenosine triphosphatedependent protein degradation (Zhang et al., 2010). Parkin KO mice, with exon 2 replaced with the neomycin-resistant gene, show mild, progressive motor deficits but normal emotionality, learning and memory (Perez and Palmiter, 2005; Harvey et al., 2008). Other parkin KO models have showed that the deletion of exon 3 resulted in reduced synaptic excitability in the nigrostriatal pathway and severe motor impairments in the beam traversal and rotarod tasks (Goldberg et al., 2003). Recent studies indicated that mice with the parkin gene deletion on exon 3 have normal olfaction, anxiety, and depressive-like behaviors, but short-term spatial memory deficits (Rial et al., 2014). However, in all of these $\mathrm{KO}$ models, the progressive loss of nigrostriatal dopaminergic neurons or enhanced vulnerability to dopaminergic neurotoxins were not observed (Rial et al., 2014). This suggests that these $\mathrm{KO}$ models may be only useful in studying the early-onset stages of PD. Other studies have created transgenic mice expressing a truncated human mutant parkin (Q311 X) driven by a Slc6a3 dopamine transporter promoter ( $\mathrm{Lu}$ et al., 2009). The parkinQ311X mice developed age-dependent dopaminergic neuron degeneration in the substantia nigra and showed late-onset and progressive motor deficits (Lu et al., 2009). This study provides evidence for dominant-negative modulatory effects of a parkin mutant on dopaminergic neuron degeneration and hypokinetic motor deficits in PD. Parkin selectively binds to PINK1 and upregulates PINK1 levels, which affects the stability, solubility, and formation of Lewy bodies (Um et al., 2009). PINK1 is a mitochondrial serine/threonine kinase, implicated in apoptosis, mitochondrial dysfunction, and impaired dopamine release (Gandhi et al., 2006). One of the first studies to generate conditional PINK1-silenced transgenic mice used the Cre/loxP inducible system to regulate the expression of PINK1 shRNA by crossing it to CMV-Cre transgenic mice (Zhou et al., 2007). However, these mice showed no striatal dopaminergic neurodegeneration or changes in nigral dopaminergic neuron numbers, and no impairments in motor activity (Zhou et al., 2007) suggesting that the silencing of PINK1 by conditional RNA interference is insufficient to cause dopaminergic neuron death salient with PD. In another study, PINK1 KO mice were created by deleting the kinase domain through introducing a nonsense mutation (Kitada et al., 2007). These KO mice had a normal number of nigral dopaminergic neurons but impairments in corticostriatal LTP and LTD that could be rescued with dopamine receptor agonists (Kitada et al., 2007). Thus, the full rescue of the synaptic deficits indicates that post-synaptic D1 and D2 receptor function is intact and suggest specific presynaptic dopaminergic defects and loss of dopaminergic terminals (Kessler et al., 2005). The precise function of DJ-1 is unknown, however, it has been found to be important in protecting mitochondria against oxidative stress, cellular transformation, transcriptional regulation, and androgen-receptor signaling (Lev et al., 2007). The DJ-1 gene encodes a ubiquitous, highly conserved protein predominantly expressed in neurons and glia cells (Canet-Aviles et al., 2004). Human studies have shown that deletion of the first five exons of the DJ-1 promoter result in progressive neurodegeneration (Bonifati et al., 2003a,b). Thus DJ-1 null mice were generated, lacking the first five exons and part of the promoter region of DJ-1, to mimic the human deletion (Chen et al., 2005). These mice showed age-dependent progression of motor deficits and significantly increased levels of striatal dopamine (Chen et al., 2005). Other studies have examined DJ-1 KO mice through disrupting exon 2, the first coding exon of DJ1 (Kim et al., 2005). These mice had no changes in nigrostriatal dopamine levels but decreased motor functions (Kim et al., 2005). Together these studies suggest that the loss of parkin, PINK1, or DJ-1 induces motor impairments consistent with the PD phenotype, though their effect on striatal dopaminergic degeneration is inconclusive. Therefore, recent studies have examined the synergistic effects of inactivating all three recessive PD genes that are believed to be essential for the survival of nigral neurons. These triple parkin, PINK1, and DJ-1 KO mice (TKO) were generated by first crossing parkin $\mathrm{KO}$ with DJ-1 KO mice, which were then interbred to obtain double parkin/DJ-1 KO mice (Kitada et al., 2009). PINK heterozygous mice were then crossed with parkin $\mathrm{KO} / \mathrm{DJ}-1$ heterozygous mice to obtain TKOs. The TKO mice were viable and fertile with no overt brain anatomical abnormalities (Kitada et al., 2009). Surprisingly, these TKO mice showed normal morphology and did not result in a loss of dopaminergic neurons in the substantia nigra and locus coeruleus at ages ranging from 3, 16, 24 months (Kitada et al., 2009). This suggests that all three recessive genes are not required 
for the survival of dopaminergic neurons but may be protective against age-dependent disruptions in PD.

\section{CONCLUSION}

In this review, we have briefly discussed selected mouse models of a number of brain disorders that are generated using genetic manipulation techniques, including transgenic mice and knockout/knock-in plus conditional Cre/loxP and inducible systems. The brain diseases that we have focused on include childhood developmental disorders such as autism, ID, FXS, and Williams-Beuren syndrome, neuropsychiatric disorders such as schizophrenia, and neurodegenerative disorders such as $\mathrm{AD}$ and PD. It is clear that availability of these mouse models has enabled systematic investigations of the in vivo function of many disease-related genes at various levels from gene to behavior, and thus contributed significantly to our understanding of the neurobiological basis of the diseases. It is expected that further analysis of these existing mice, plus additional models with more

\section{REFERENCES}

Abazyan, S., and Pletnikov, M. V. (2014). "Schizophrenia," in Behavioural Genetics of the Mouse: Genetic Mouse Models of Neurobehavioral Disorders, eds F. S. S. Pietropaolo and W. E. Crusio (Cambridge: Cambridge University Press), 189-207.

Ahn, T. B., Kim, S. Y., Kim, J. Y., Park, S. S., Lee, D. S., Min, H. J., et al. (2008). alphaSynuclein gene duplication is present in sporadic Parkinson disease. Neurology 70, 43-49. doi: 10.1212/01.wnl.0000271080.53272.c7

Allen, K. M., Gleeson, J. G., Bagrodia, S., Partington, M. W., MacMillan, J. C., Cerione, R. A., et al. (1998). PAK3 mutation in nonsyndromic X-linked mental retardation. Nat. Genet. 20, 25-30. doi: 10.1038/1675

Amiri, A., Sanchez-Ortiz, E., Cho, W., Birnbaum, S. G., Xu, J., McKay, R. M., et al. (2014). Analysis of FMR1 deletion in a subpopulation of post-mitotic neurons in mouse cortex and hippocampus. Autism Res. 7, 60-71. doi: 10.1002/ aur. 1342

Anderson, G. R., Galfin, T., Xu, W., Aoto, J., Malenka, R. C., and Sudhof, T. C. (2012). Candidate autism gene screen identifies critical role for celladhesion molecule CASPR2 in dendritic arborization and spine development. Proc. Natl. Acad. Sci. U.S.A. 109, 18120-18125. doi: 10.1073/pnas.12163 98109

Andres-Mateos, E., Mejias, R., Sasaki, M., Li, X., Lin, B. M., Biskup, S., et al. (2009). Unexpected lack of hypersensitivity in LRRK2 knock-out mice to MPTP (1-methyl-4-phenyl-1,2,3,6-tetrahydropyridine). J. Neurosci. 29, 15846-15850. doi: 10.1523/JNEUROSCI.4357-09.2009

Arber, S., Barbayannis, F. A., Hanser, H., Schneider, C., Stanyon, C. A., Bernard, O., et al. (1998). Regulation of actin dynamics through phosphorylation of cofilin by LIM-kinase. Nature 393, 805-809. doi: 10.1038/31729

Arendash, G. W., King, D. L., Gordon, M. N., Morgan, D., Hatcher, J. M., Hope, C. E., et al. (2001). Progressive, age-related behavioral impairments in transgenic mice carrying both mutant amyloid precursor protein and presenilin-1 transgenes. Brain Res. 891, 42-53. doi: 10.1016/S00068993(00)03186-3

Arking, D. E., Cutler, D. J., Brune, C. W., Teslovich, T. M., West, K., Ikeda, M., et al. (2008). A common genetic variant in the neurexin superfamily member CNTNAP2 increases familial risk of autism. Am. J. Hum. Genet. 82, 160-164. doi: 10.1016/j.ajhg.2007.09.015

Arnold, S. E., Hyman, B. T., Flory, J., Damasio, A. R., and Van Hoesen, G. W. (1991). The topographical and neuroanatomical distribution of neurofibrillary tangles and neuritic plaques in the cerebral cortex of patients with Alzheimer's disease. Cereb. Cortex 1, 103-116. doi: 10.1093/cercor/1. 1.103 precise spatial and temporal specificity, will continue to reveal new findings that will enhance our understanding and treatment of various brain diseases.

\section{AUTHOR CONTRIBUTIONS}

All authors listed, have made substantial, direct and intellectual contribution to the work, and approved it for publication.

\section{ACKNOWLEDGMENTS}

This work has been supported by Canadian Institutes of Health Research (CIHR, MOP119421, ZPJ), Canadian Natural Science and Engineering Research Council (NSERC, RGPIN341498, ZPJ), China-Canada CIHR Joint Health Research Initiative Program (CCI117959, ZPJ) and the Hospital for Sick Children Foundation.

Ascano, M. Jr., Mukherjee, N., Bandaru, P., Miller, J. B., Nusbaum, J. D., Corcoran, D. L., et al. (2012). FMRP targets distinct mRNA sequence elements to regulate protein expression. Nature 492, 382-386. doi: 10.1038/nature 11737

Asrar, S., Meng, Y., Zhou, Z., Todorovski, Z., Huang, W. W., and Jia, Z. (2009). Regulation of hippocampal long-term potentiation by p21activated protein kinase 1 (PAK1). Neuropharmacology 56, 73-80. doi: 10.1016/j.neuropharm.2008.06.055

Austin, C. P., Ky, B., Ma, L., Morris, J. A., and Shughrue, P. J. (2004). Expression of disrupted-in-schizophrenia-1, a schizophrenia-associated gene, is prominent in the mouse hippocampus throughout brain development. Neuroscience 124, 3-10. doi: 10.1016/j.neuroscience.2003.11.010

Autism Genome Project, C., Szatmari, P., Paterson, A. D., Zwaigenbaum, L., Roberts, W., Brian, J., et al. (2007). Mapping autism risk loci using genetic linkage and chromosomal rearrangements. Nat. Genet. 39, 319-328. doi: $10.1038 / \mathrm{ng} 1985$

Ayalew, M., Le-Niculescu, H., Levey, D. F., Jain, N., Changala, B., Patel, S. D., et al. (2012). Convergent functional genomics of schizophrenia: from comprehensive understanding to genetic risk prediction. Mol. Psychiatry 17, 887-905. doi: 10.1038/mp.2012.37

Bakker, C. E., Verheij, C., Willemsen, R., Vanderhelm, R., Oerlemans, F., Vermey, M., et al. (1994). Fmrl knockout mice: a model to study fragile X mental retardation. Cell 78, 23-33.

Baskaran, Y., Ng, Y. W., Selamat, W., Ling, F. T., and Manser, E. (2012). Group I and II mammalian PAKs have different modes of activation by Cdc42. EMBO Rep. 13, 653-659. doi: 10.1038/embor.2012.75

Basuta, K., Narcisa, V., Chavez, A., Kumar, M., Gane, L., Hagerman, R., et al. (2011). Clinical phenotypes of a juvenile sibling pair carrying the fragile $\mathrm{X}$ premutation. Am. J. Med. Genet. A 155A, 519-525. doi: 10.1002/ajmg.a.33446

Bayer, T. A., Cappai, R., Masters, C. L., Beyreuther, K., and Multhaup, G. (1999). It all sticks together-the APP-related family of proteins and Alzheimer's disease. Mol. Psychiatry 4, 524-528. doi: 10.1038/sj.mp.4000552

Berry-Kravis, E., Abrams, L., Coffey, S. M., Hall, D. A., Greco, C., Gane, L. W., et al. (2007). Fragile X-associated tremor/ataxia syndrome: clinical features, genetics, and testing guidelines. Mov. Disord. 22, 2018-2030. doi: 10.1002/mds. 21493

Blundell, J., Blaiss, C. A., Etherton, M. R., Espinosa, F., Tabuchi, K., Walz, C., et al. (2010). Neuroligin-1 deletion results in impaired spatial memory and increased repetitive behavior. J. Neurosci. 30, 2115-2129. doi: 10.1523/JNEUROSCI.451709.2010

Bockers, T. M., Mameza, M. G., Kreutz, M. R., Bockmann, J., Weise, C., Buck, F., et al. (2001). Synaptic scaffolding proteins in rat brain. Ankyrin 
repeats of the multidomain Shank protein family interact with the cytoskeletal protein alpha-fodrin. J. Biol. Chem. 276, 40104-40112. doi: 10.1074/jbc.M102 454200

Boda, B., Alberi, S., Nikonenko, I., Node-Langlois, R., Jourdain, P., Moosmayer, M., et al. (2004). The mental retardation protein PAK3 contributes to synapse formation and plasticity in hippocampus. J. Neurosci. 24, 10816-10825. doi: 10.1523/JNEUROSCI.2931-04.2004

Bolivar, V. J. (2014). "Social dysfunction and mental retardation- autism," in Behavioral Genetics of the Mouse: Genetic Mouse Models of Neurobehavioural Disorders, eds S. Pietropaolo, F. Sluyter, and W. E. Crusio (Cambridge: Cambridge University Press), 113-133.

Bonifati, V., Rizzu, P., Squitieri, F., Krieger, E., Vanacore, N., van Swieten, J. C., et al. (2003a). DJ-1( PARK7), a novel gene for autosomal recessive, early onset parkinsonism. Neurol. Sci. 24, 159-160. doi: 10.1007/s10072-003-0108-0

Bonifati, V., Rizzu, P., van Baren, M. J., Schaap, O., Breedveld, G. J., Krieger, E., et al. (2003b). Mutations in the DJ-1 gene associated with autosomal recessive early-onset parkinsonism. Science 299, 256-259. doi: 10.1126/science.10 77209

Bontekoe, C. J., McIlwain, K. L., Nieuwenhuizen, I. M., Yuva-Paylor, L. A., Nellis, A., Willemsen, R., et al. (2002). Knockout mouse model for Fxr2: a model for mental retardation. Hum. Mol. Genet. 11, 487-498. doi: 10.1093/hmg/11.5.487

Borchelt, D. R., Thinakaran, G., Eckman, C. B., Lee, M. K., Davenport, F., Ratovitsky, T., et al. (1996). Familial Alzheimer's disease-linked presenilin 1 variants elevate Abeta1-42/1-40 ratio in vitro and in vivo. Neuron 17, 10051013. doi: 10.1016/S0896-6273(00)80230-5

Bozdagi, O., Sakurai, T., Papapetrou, D., Wang, X., Dickstein, D. L., Takahashi, N., et al. (2010). Haploinsufficiency of the autism-associated Shank3 gene leads to deficits in synaptic function, social interaction, and social communication. Mol. Autism 1:15. doi: 10.1186/2040-2392-1-15

Braak, H., and Braak, E. (1994). Morphological criteria for the recognition of Alzheimer's disease and the distribution pattern of cortical changes related to this disorder. Neurobiol. Aging 15, 355-356, discussion 379-380. doi: 10.1016/0197-4580(94)90032-9

Braak, H., Del Tredici, K., Rub, U., de Vos, R. A., Jansen Steur, E. N., and Braak, E. (2003). Staging of brain pathology related to sporadic Parkinson's disease. Neurobiol. Aging 24, 197-211. doi: 10.1016/S0197-4580(02)00065-9

Brandon, N. J., Millar, J. K., Korth, C., Sive, H., Singh, K. K., and Sawa, A. (2009). Understanding the role of DISC1 in psychiatric disease and during normal development. J. Neurosci. 29, 12768-12775. doi: 10.1523/JNEUROSCI.335509.2009

Bregman, J. D., Leckman, J. F., and Ort, S. I. (1988). Fragile X syndrome: genetic predisposition to psychopathology. J. Autism. Dev. Disord. 18, 343-354. doi: 10.1007/BF02212191

Brennan, F. X., Albeck, D. S., and Paylor, R. (2006). Fmr1 knockout mice are impaired in a leverpress escape/avoidance task. Genes Brain Behav. 5, 467-471. doi: 10.1111/j.1601-183X.2005.00183.x

Britsch, S. (2007). The neuregulin-I/ErbB signaling system in development and disease. Adv. Anat. Embryol. Cell Biol. 190, 1-65.

Burden, S., and Yarden, Y. (1997). Neuregulins and their receptors: a versatile signaling module in organogenesis and oncogenesis. Neuron 18, 847-855. doi: 10.1016/S0896-6273(00)80324-4

Burre, J., Sharma, M., Tsetsenis, T., Buchman, V., Etherton, M. R., and Sudhof, T. C. (2010). Alpha-synuclein promotes SNARE-complex assembly in vivo and in vitro. Science 329, 1663-1667. doi: 10.1126/science.1195227

Calhoun, M. E., Wiederhold, K. H., Abramowski, D., Phinney, A. L., Probst, A., Sturchler-Pierrat, C., et al. (1998). Neuron loss in APP transgenic mice. Nature 395, 755-756. doi: 10.1038/27351

Camargo, L. M., Collura, V., Rain, J. C., Mizuguchi, K., Hermjakob, H., Kerrien, S., et al. (2007). Disrupted in schizophrenia 1 interactome: evidence for the close connectivity of risk genes and a potential synaptic basis for schizophrenia. Mol. Psychiatry 12, 74-86. doi: 10.1038/sj.mp.4001880

Canet-Aviles, R. M., Wilson, M. A., Miller, D. W., Ahmad, R., McLendon, C., Bandyopadhyay, S., et al. (2004). The Parkinson's disease protein DJ-1 is neuroprotective due to cysteine-sulfinic acid-driven mitochondrial localization. Proc. Natl. Acad. Sci. U.S.A. 101, 9103-9108. doi: 10.1073/pnas.0402 959101
Carlsson, A., and Lindqvist, M. (1963). Effect of chlorpromazine or haloperidol on formation of 3methoxytyramine and normetanephrine in mouse brain. Acta Pharmacol. Toxicol. (Copenh) 20, 140-144. doi: 10.1111/j.1600-0773.1963.tb01730.x

Chandra, S., Fornai, F., Kwon, H. B., Yazdani, U., Atasoy, D., Liu, X., et al. (2004). Double-knockout mice for alpha- and beta-synucleins: effect on synaptic functions. Proc. Natl. Acad. Sci. U.S.A. 101, 14966-14971. doi: 10.1073/pnas.0406283101

Chandra, S., Gallardo, G., Fernandex-Chancon, R., Schluter, O. M., and Sudhof, T. C. (2005). alpha-synuclein cooperates with CSPalpha in preventing neurodegeneration. Cell 123, 383-396. doi: 10.1016/j.cell.2005. 09.028

Chandran, J. S., Kazanis, I., Clapcote, S. J., Ogawa, F., Millar, J. K., Porteous, D. J., et al. (2014). Discl variation leads to specific alterations in adult neurogenesis. PLoS ONE 9:e108088. doi: 10.1371/journal.pone.01 08088

Chelly, J., and Mandel, J. L. (2001). Monogenic causes of X-linked mental retardation. Nat. Rev. Genet. 2, 669-680. doi: 10.1038/35088558

Chen, C. Y., Weng, Y. H., Chien, K. Y., Lin, K. J., Yeh, T. H., Cheng, Y. P., et al. (2012). (G2019S) LRRK2 activates MKK4-JNK pathway and causes degeneration of SN dopaminergic neurons in a transgenic mouse model of PD. Cell Death. Differ. 19, 1623-1633. doi: 10.1038/cdd.2012.42

Chen, L., Cagniard, B., Mathews, T., Jones, S., Koh, H. C., Ding, Y., et al. (2005). Age-dependent motor deficits and dopaminergic dysfunction in DJ-1 null mice. J. Biol. Chem. 280, 21418-21426. doi: 10.1074/jbc.M4139 55200

Chonchaiya, W., Au, J., Schneider, A., Hessl, D., Harris, S. W., Laird, M., et al. (2012). Increased prevalence of seizures in boys who were probands with the FMR1 premutation and co-morbid autism spectrum disorder. Hum. Genet. 131, 581-589. doi: 10.1007/s00439-011-1106-6

Chubb, J. E., Bradshaw, N. J., Soares, D. C., Porteous, D. J., and Millar, J. K. (2008). The DISC locus in psychiatric illness. Mol. Psychiatry 13, 36-64. doi: 10.1038/sj.mp.4002106

Clapcote, S. J., Lipina, T. V., Millar, J. K., Mackie, S., Christie, S., Ogawa, F., et al. (2007). Behavioral phenotypes of Disc1 missense mutations in mice. Neuron 54, 387-402. doi: 10.1016/j.neuron.2007.04.015

Clark, L. N., Poorkaj, P., Wszolek, Z., Geschwind, D. H., Nasreddine, Z. S., Miller, B., et al. (1998). Pathogenic implications of mutations in the tau gene in pallido-ponto-nigral degeneration and related neurodegenerative disorders linked to chromosome 17. Proc. Natl. Acad. Sci. U.S.A. 95, 13103-13107. doi: 10.1073/pnas.95.22.13103

Coghill, E. L., Hugill, A., Parkinson, N., Davison, C., Glenister, P., Clements, S., et al. (2002). A gene-driven approach to the identification of ENU mutants in the mouse. Nat. Genet. 30, 255-256. doi: 10.1038/ng847

Comery, T. A., Martone, R. L., Aschmies, S., Atchison, K. P., Diamantidis, G., Gong, X., et al. (2005). Acute gamma-secretase inhibition improves contextual fear conditioning in the Tg2576 mouse model of Alzheimer's disease. J. Neurosci. 25, 8898-8902. doi: 10.1523/JNEUROSCI.269 3-05.2005

Cookson, M. R., and van der Brug, M. (2008). Cell systems and the toxic mechanism(s) of alpha-synuclein. Exp. Neurol. 209, 5-11. doi: 10.1016/j.expneurol.2007.05.022

Coyle, J. T. (2006). Substance use disorders and Schizophrenia: a question of shared glutamatergic mechanisms. Neurotox. Res. 10, 221-233. doi: 10.1007/BF03033359

Crawford, D. C., Acuna, J. M., and Sherman, S. L. (2001). FMR1 and the fragile X syndrome: human genome epidemiology review. Genet. Med. 3, 359-371. doi: 10.1097/00125817-200109000-00006

Dachtler, J., Ivorra, J. L., Rowland, T. E., Lever, C., Rodgers, R. J., and Clapcote, S. J. (2015). Heterozygous deletion of alpha-neurexin I or alpha-neurexin II results in behaviors relevant to autism and schizophrenia. Behav. Neurosci. 129, 765-776. doi: 10.1037/bne0000108

Dahlhaus, R., Hines, R. M., Eadie, B. D., Kannangara, T. S., Hines, D. J., Brown, C. E., et al. (2010). Overexpression of the cell adhesion protein neuroligin-1 induces learning deficits and impairs synaptic plasticity by altering the ratio of excitation to inhibition in the hippocampus. Hippocampus 20, 305-322. doi: 10.1002/hipo.20630 
Davis, K. L., Kahn, R. S., Ko, G., and Davidson, M. (1991). Dopamine in schizophrenia: a review and reconceptualization. Am. J. Psychiatry 148, 14741486. doi: 10.1176/ajp.148.11.1474

Dawson, H. N., Ferreira, A., Eyster, M. V., Ghoshal, N., Binder, L. I., and Vitek, M. P. (2001). Inhibition of neuronal maturation in primary hippocampal neurons from tau deficient mice. J. Cell Sci. 114, 1179-1187.

De Strooper, B. (2007). Loss-of-function presenilin mutations in Alzheimer disease. Talking Point on the role of presenilin mutations in Alzheimer disease. EMBO Rep. 8, 141-146. doi: 10.1038/sj.embor.7400897

DesMarais, V., Ghosh, M., Eddy, R., and Condeelis, J. (2005). Cofilin takes the lead. J. Cell Sci. 118, 19-26. doi: 10.1242/jcs.01631

Devys, D., Lutz, Y., Rouyer, N., Bellocq, J. P., and Mandel, J. L. (1993). The FMR1 protein is cytoplasmic, most abundant in neurons and appears normal in carriers of a fragile X premutation. Nat. Genet. 4, 335-340. doi: 10.1038/ng08 93-335

Dodart, J. C., Meziane, H., Mathis, C., Bales, K. R., Paul, S. M., and Ungerer, A. (1999). Behavioral disturbances in transgenic mice overexpressing the V717F beta-amyloid precursor protein. Behav. Neurosci. 113, 982-990. doi: 10.1037/0735-7044.113.5.982

Drolet, R. E., Behrouz, B., Lookingland, K. J., and Goudreau, J. L. (2004). Mice lacking alpha-synuclein have an attenuated loss of striatal dopamine following prolonged chronic MPTP administration. Neurotoxicology 25, 761-769. doi: 10.1016/j.neuro.2004.05.002

Dubos, A., Combeau, G., Bernardinelli, Y., Barnier, J. V., Hartley, O., Gaertner, H., et al. (2012). Alteration of synaptic network dynamics by the intellectual disability protein PAK3. J. Neurosci. 32, 519-527. doi: 10.1523/JNEUROSCI.3252-11.2012

Duffy, L., Cappas, E., Scimone, A., Schofield, P. R., and Karl, T. (2008). Behavioral profile of a heterozygous mutant mouse model for EGF-like domain neuregulin 1. Behav. Neurosci. 122, 748-759. doi: 10.1037/0735-7044.122. 4.748

Duncan, G., Miyamoto, S., Gu, H., Lieberman, J., Koller, B., and Snouwaert, J. (2002). Alterations in regional brain metabolism in genetic and pharmacological models of reduced NMDA receptor function. Brain Res. 951, 166-176. doi: 10.1016/S0006-8993(02)03156-6

Durand, C. M., Betancur, C., Boeckers, T. M., Bockmann, J., Chaste, P., Fauchereau, F., et al. (2007). Mutations in the gene encoding the synaptic scaffolding protein SHANK3 are associated with autism spectrum disorders. Nat. Genet. 39, 25-27. doi: 10.1038/ng1933

Durieux, A. M., Horder, J., and Petrinovic, M. M. (2015). Neuroligin-2 and the tightrope of excitation/inhibition balance in the prefrontal cortex. J. Neurophysiol. 115, 5-7. doi: 10.1152/jn.00703.2015

Eberhard, D., and Grummt, I. (1996). Species specificity of ribosomal gene transcription: a factor associated with human RNA polymerase I prevents transcription of mouse rDNA. DNA Cell Biol. 15, 167-173. doi: 10.1089/dna.1996.15.167

Elder, G. A., Gama Sosa, M. A., De Gasperi, R., Dickstein, D. L., and Hof, P. R. (2010). Presenilin transgenic mice as models of Alzheimer's disease. Brain Struct. Funct. 214, 127-143. doi: 10.1007/s00429-0090227-3

Etherton, M. R., Blaiss, C. A., Powell, C. M., and Sudhof, T. C. (2009). Mouse neurexin-1alpha deletion causes correlated electrophysiological and behavioral changes consistent with cognitive impairments. Proc. Natl. Acad. Sci. U.S.A. 106, 17998-18003. doi: 10.1073/pnas.0910297106

Ey, E., Yang, M., Katz, A. M., Woldeyohannes, L., Silverman, J. L., Leblond, C. S., et al. (2012). Absence of deficits in social behaviors and ultrasonic vocalizations in later generations of mice lacking neuroligin4. Genes Brain Behav. 11, 928941. doi: 10.1111/j.1601-183X.2012.00849.x

Fearnley, J. M., and Lees, A. J. (1991). Ageing and Parkinson's disease: substantia nigra regional selectivity. Brain 114(Pt 5), 2283-2301. doi: 10.1093/brain/114.5.2283

Feng, R., Wang, H., Wang, J., Shrom, D., Zheng, X., and Tsien, J. Z. (2004). Forebrain degeneration and ventricle enlargement caused by double knockout of Alzheimer's presenilin-1 and presenilin-2. Proc. Natl. Acad. Sci. U.S.A. 101, 8162-8167. doi: 10.1073/pnas.0402733101

Field, J., and Manser, E. (2012). The PAKs come of age: celebrating 18 years of discovery. Cell. Logist. 2, 54-58. doi: 10.4161/cl.22084
Foldy, C., Malenka, R. C., and Sudhof, T. C. (2013). Autism-associated neuroligin3 mutations commonly disrupt tonic endocannabinoid signaling. Neuron 78 , 498-509. doi: 10.1016/j.neuron.2013.02.036

Forno, L. S. (1996). Neuropathology of Parkinson's disease. J. Neuropathol. Exp. Neurol. 55, 259-272. doi: 10.1097/00005072-199603000-00001

Frangiskakis, J. M., Ewart, A. K., Morris, C. A., Mervis, C. B., Bertrand, J., Robinson, B. F., et al. (1996). LIM-kinase1 hemizygosity implicated in impaired visuospatial constructive cognition. Cell 86, 59-69. doi: 10.1016/S00928674(00)80077-X

Fridell, R. A., Benson, R. E., Hua, J., Bogerd, H. P., and Cullen, B. R. (1996). A nuclear role for the Fragile $\mathrm{X}$ mental retardation protein. EMBO J. 15, 5408-5414.

Fu, Y. H., Kuhl, D. P., Pizzuti, A., Pieretti, M., Sutcliffe, J. S., Richards, S., et al. (1991). Variation of the CGG repeat at the fragile $\mathrm{X}$ site results in genetic instability: resolution of the Sherman paradox. Cell 67, 1047-1058. doi: 10.1016/0092-8674(91)90283-5

Games, D., Adams, D., Alessandrini, R., Barbour, R., Berthelette, P., Blackwell, C., et al. (1995). Alzheimer-type neuropathology in transgenic mice overexpressing V717F beta-amyloid precursor protein. Nature 373, 523-527. doi: $10.1038 / 373523 \mathrm{a} 0$

Gandhi, S., Muqit, M. M., Stanyer, L., Healy, D. G., Abou-Sleiman, P. M., Hargreaves, I., et al. (2006). PINK1 protein in normal human brain and Parkinson's disease. Brain 129, 1720-1731. doi: 10.1093/brain/awl114

Gasser, T. (2009). Genomic and proteomic biomarkers for Parkinson disease. Neurology 72, S27-S31. doi: 10.1212/WNL.0b013e318198e054

Gdalyahu, A., Lazaro, M., Penagarikano, O., Golshani, P., Trachtenberg, J. T., and Geschwind, D. H. (2015). The autism related protein contactin-associated protein-like 2 (CNTNAP2) stabilizes new spines: an in vivo mouse study. PLoS ONE 10:e0125633. doi: 10.1371/journal.pone.0125633

Gerlai, R., Pisacane, P., and Erickson, S. (2000). Heregulin, but not ErbB2 or ErbB3, heterozygous mutant mice exhibit hyperactivity in multiple behavioral tasks. Behav. Brain Res. 109, 219-227. doi: 10.1016/S0166-4328(99) 00175-8

Gilks, W. P., Abou-Sleiman, P. M., Gandhi, S., Jain, S., Singleton, A., Lees, A. J., et al. (2005). A common LRRK2 mutation in idiopathic Parkinson's disease. Lancet 365, 415-416. doi: 10.1016/S0140-6736(05)17830-1

Gillardon, F. (2009). Leucine-rich repeat kinase 2 phosphorylates brain tubulinbeta isoforms and modulates microtubule stability-a point of convergence in parkinsonian neurodegeneration? J. Neurochem. 110, 1514-1522. doi: 10.1111/j.1471-4159.2009.06235.x

Glessner, J. T., Wang, K., Cai, G., Korvatska, O., Kim, C. E., Wood, S., et al. (2009). Autism genome-wide copy number variation reveals ubiquitin and neuronal genes. Nature 459, 569-573. doi: 10.1038/nature07953

Goate, A., Chartier-Harlin, M. C., Mullan, M., Brown, J., Crawford, F., Fidani, L., et al. (1991). Segregation of a missense mutation in the amyloid precursor protein gene with familial Alzheimer's disease. Nature 349, 704-706. doi: $10.1038 / 349704 \mathrm{a} 0$

Goedert, M. (2005). Tau gene mutations and their effects. Mov. Disord. 20(Suppl. 12), S45-S52. doi: 10.1002/mds.20539

Goldberg, M. S., Fleming, S. M., Palacino, J. J., Cepeda, C., Lam, H. A., Bhatnagar, A., et al. (2003). Parkin-deficient mice exhibit nigrostriatal deficits but not loss of dopaminergic neurons. J. Biol. Chem. 278, 43628-43635. doi: 10.1074/jbc.M308947200

Gordon, A., Adamsky, K., Vainshtein, A., Frechter, S., Dupree, J. L., Rosenbluth, J., et al. (2014). Caspr and caspr2 are required for both radial and longitudinal organization of myelinated axons. J. Neurosci. 34, 14820-14826. doi: 10.1523/JNEUROSCI.3369-14.2014

Greten-Harrison, B., Polydoro, M., Morimoto-Tomita, M., Diao, L., Williams, A. M., Nie, E. H., et al. (2010). alphabetagamma-synuclein triple knockout mice reveal age-dependent neuronal dysfunction. Proc. Natl. Acad. Sci. U.S.A. 107, 19573-19578. doi: 10.1073/pnas.1005005107

Hall, A. M., and Roberson, E. D. (2012). Mouse models of Alzheimer's disease. Brain Res. Bull. 88, 3-12. doi: 10.1016/j.brainresbull.2011.11.017

Hammer, M., Krueger-Burg, D., Tuffy, L. P., Cooper, B. H., Taschenberger, H., Goswami, S. P., et al. (2015). Perturbed hippocampal synaptic inhibition and gamma-oscillations in a neuroligin-4 knockout mouse model of autism. Cell Rep. 13, 516-523. doi: 10.1016/j.celrep.2015.09.011 
Harada, A., Oguchi, K., Okabe, S., Kuno, J., Terada, S., Ohshima, T., et al. (1994). Altered microtubule organization in small-calibre axons of mice lacking tau protein. Nature 369, 488-491. doi: 10.1038/369488a0

Harrison, P. J., and Law, A. J. (2006). Neuregulin 1 and schizophrenia: genetics, gene expression, and neurobiology. Biol. Psychiatry 60, 132-140. doi: 10.1016/j.biopsych.2005.11.002

Harvey, B. K., Wang, Y., and Hoffer, B. J. (2008). Transgenic rodent models of Parkinson's disease. Acta Neurochir. Suppl. 101, 89-92. doi: 10.1007/978-3-21178205-7_15

Hayashi, M. L., Choi, S. Y., Rao, B. S., Jung, H. Y., Lee, H. K., Zhang, D., et al. (2004). Altered cortical synaptic morphology and impaired memory consolidation in forebrain- specific dominant-negative PAK transgenic mice. Neuron 42, 773-787. doi: 10.1016/j.neuron.2004.05.003

Hayashi, M. L., Rao, B. S., Seo, J. S., Choi, H. S., Dolan, B. M., Choi, S. Y., et al. (2007). Inhibition of p21-activated kinase rescues symptoms of fragile X syndrome in mice. Proc. Natl. Acad. Sci. U.S.A. 104, 11489-11494. doi: 10.1073/pnas.0705003104

Herzig, M. C., Bidinosti, M., Schweizer, T., Hafner, T., Stemmelen, C., Weiss, A., et al. (2012). High LRRK2 levels fail to induce or exacerbate neuronal alpha-synucleinopathy in mouse brain. PLoS ONE 7:e36581. doi: 10.1371/journal.pone.0036581

Hikida, T., Jaaro-Peled, H., Seshadri, S., Oishi, K., Hookway, C., Kong, S., et al. (2007). Dominant-negative DISC1 transgenic mice display schizophreniaassociated phenotypes detected by measures translatable to humans. Proc. Natl. Acad. Sci. U.S.A. 104, 14501-14506. doi: 10.1073/pnas.07047 74104

Hines, R. M., Wu, L., Hines, D. J., Steenland, H., Mansour, S., Dahlhaus, R., et al. (2008). Synaptic imbalance, stereotypies, and impaired social interactions in mice with altered neuroligin 2 expression. J. Neurosci. 28, 6055-6067. doi: 10.1523/JNEUROSCI.0032-08.2008

Hinton, V. J., Brown, W. T., Wisniewski, K., and Rudelli, R. D. (1991). Analysis of neocortex in three males with the fragile X syndrome. Am. J. Med. Genet. 41, 289-294. doi: 10.1002/ajmg.1320410306

Hirtz, D., Thurman, D. J., Gwinn-Hardy, K., Mohamed, M., Chaudhuri, A. R., and Zalutsky, R. (2007). How common are the "common" neurologic disorders? Neurology 68, 326-337. doi: 10.1212/01.wnl.0000252807.38124.a3

Holmes, W. E., Sliwkowski, M. X., Akita, R. W., Henzel, W. J., Lee, J., Park, J. W., et al. (1992). Identification of heregulin, a specific activator of p185erbB2. Science 256, 1205-1210. doi: 10.1126/science.256.5060.1205

Hoogenraad, C. C., Koekkoek, B., Akhmanova, A., Krugers, H., Dortland, B., Miedema, M., et al. (2002). Targeted mutation of Cyln2 in the Williams syndrome critical region links CLIP-115 haploinsufficiency to neurodevelopmental abnormalities in mice. Nat. Genet. 32, 116-127. doi: $10.1038 / \mathrm{ng} 954$

Howes, O. D., and Kapur, S. (2009). The dopamine hypothesis of schizophrenia: version III-the final common pathway. Schizophr. Bull. 35, 549-562. doi: $10.1093 / \mathrm{schbul} / \mathrm{sbp} 006$

Hsiao, K. (1998). Transgenic mice expressing Alzheimer amyloid precursor proteins. Exp. Gerontol. 33, 883-889. doi: 10.1016/S0531-5565(98)00045-X

Huang, W., Zhou, Z., Asrar, S., Henkelman, M., Xie, W., and Jia, Z. (2011). p21-Activated kinases 1 and 3 control brain size through coordinating neuronal complexity and synaptic properties. Mol. Cell. Biol. 31, 388-403. doi: 10.1128/MCB.00969-10

Hutton, M., Lendon, C. L., Rizzu, P., Baker, M., Froelich, S., Houlden, H., et al. (1998). Association of missense and 5'-splice-site mutations in tau with the inherited dementia FTDP-17. Nature 393, 702-705. doi: 10.1038/ 31508

Ichtchenko, K., Hata, Y., Nguyen, T., Ullrich, B., Missler, M., Moomaw, C., et al. (1995). Neuroligin 1: a splice site-specific ligand for beta-neurexins. Cell 81, 435-443. doi: 10.1016/0092-8674(95)90396-8

Ikegami, S., Harada, A., and Hirokawa, N. (2000). Muscle weakness, hyperactivity, and impairment in fear conditioning in tau-deficient mice. Neurosci. Lett. 279, 129-132. doi: 10.1016/S0304-3940(99)00964-7

Irwin, S. A., Patel, B., Idupulapati, M., Harris, J. B., Crisostomo, R. A., Larsen, B. P., et al. (2001). Abnormal dendritic spine characteristics in the temporal and visual cortices of patients with fragile-X syndrome: a quantitative examination. Am. J. Med. Genet. 98, 161-167. doi: 10.1002/1096-8628(20010115)98:2<161::AIDAJMG1025 > 3.0.CO;2-B
Jamain, S., Radyushkin, K., Hammerschmidt, K., Granon, S., Boretius, S., Varoqueaux, F., et al. (2008). Reduced social interaction and ultrasonic communication in a mouse model of monogenic heritable autism. Proc. Natl. Acad. Sci. U.S.A. 105, 1710-1715. doi: 10.1073/pnas.0711555105

Jankovic, J. (2008). Parkinson's disease: clinical features and diagnosis. J. Neurol. Neurosurg. Psychiatry 79, 368-376. doi: 10.1136/jnnp.2007.131045

Janus, C., and Borchelt, D. (2014). "Alzheimer's disease," in Behavioral Genetics of the Mouse: Genetic Mouse Models of Neurobehavioral Disorders, eds F. S. S. Pietropaolo and W. E. Crusio (Cambridge: Cambridge University Press), 391-410.

Janus, C., D’Amelio, S., Amitay, O., Chishti, M. A., Strome, R., Fraser, P., et al. (2000). Spatial learning in transgenic mice expressing human presenilin 1 (PS1) transgenes. Neurobiol. Aging 21, 541-549. doi: 10.1016/S0197-4580(00) 00107-X

Jaramillo, T. C., Speed, H. E., Xuan, Z., Reimers, J. M., Liu, S., and Powell, C. M. (2015). Altered striatal synaptic function and abnormal behaviour in shank3 exon4-9 deletion mouse model of autism. Autism Res. doi: 10.1002/aur.1529 [Epub ahead of print].

Javitt, D. C. (2007). Glutamate and schizophrenia: phencyclidine, N-methyl-Daspartate receptors, and dopamine-glutamate interactions. Int. Rev. Neurobiol. 78, 69-108. doi: 10.1016/S0074-7742(06)78003-5

Javitt, D. C., and Zukin, S. R. (1991). Recent advances in the phencyclidine model of schizophrenia. Am. J. Psychiatry 148, 1301-1308. doi: 10.1176/ajp.148. 10.1301

Jedlicka, P., Vnencak, M., Krueger, D. D., Jungenitz, T., Brose, N., and Schwarzacher, S. W. (2013). Neuroligin-1 regulates excitatory synaptic transmission, LTP and EPSP-spike coupling in the dentate gyrus in vivo. Brain Struct. Funct. doi: 10.1007/s00429-013-0636-1PMID:NOPMID [Epub ahead of print].

Jia, Z. P., Todorovski, Z., Meng, Y. H., Asrar, S., and Wang, L. Y. (2009). "LIMK1 and actin regulation of spine and synaptic function," in New Encyclopedia of Neuroscience, ed. L. R. Squire (Oxford: Academic Press), 467-472.

Juan, L. W., Liao, C. C., Lai, W. S., Chang, C. Y., Pei, J. C., Wong, W. R., et al. (2014). Phenotypic characterization of C57BL/6J mice carrying the Disc1 gene from the 129S6/SvEv strain. Brain Struct. Funct. 219, 1417-1431. doi: 10.1007/s00429-013-0577-8

Karl, T., Duffy, L., Scimone, A., Harvey, R. P., and Schofield, P. R. (2007). Altered motor activity, exploration and anxiety in heterozygous neuregulin 1 mutant mice: implications for understanding schizophrenia. Genes Brain Behav. 6, 677-687. doi: 10.1111/j.1601-183X.2006.00298.x

Kato, T., Kasai, A., Mizuno, M., Fengyi, L., Shintani, N., Maeda, S., et al. (2010). Phenotypic characterization of transgenic mice overexpressing neuregulin-1. PLoS ONE 5:e14185. doi: 10.1371/journal.pone.0014185

Kawarabayashi, T., Younkin, L. H., Saido, T. C., Shoji, M., Ashe, K. H., and Younkin, S. G. (2001). Age-dependent changes in brain, CSF, and plasma amyloid (beta) protein in the Tg2576 transgenic mouse model of Alzheimer's disease. J. Neurosci. 21, 372-381.

Kellendonk, C., Simpson, E. H., Polan, H. J., Malleret, G., Vronskaya, S., Winiger, V., et al. (2006). Transient and selective overexpression of dopamine D2 receptors in the striatum causes persistent abnormalities in prefrontal cortex functioning. Neuron 49, 603-615. doi: 10.1016/j.neuron.2006. 01.023

Kelly, M. L., and Chernoff, J. (2012). Mouse models of PAK function. Cell Logist. 2, 84-88. doi: $10.4161 / \mathrm{cl} .21381$

Kessler, K. R., Hamscho, N., Morales, B., Menzel, C., Barrero, F., Vives, F., et al. (2005). Dopaminergic function in a family with the PARK6 form of autosomal recessive Parkinson's syndrome. J. Neural Transm. (Vienna) 112, 1345-1353. doi: 10.1007/s00702-005-0281-9

Kim, J., Jung, S. Y., Lee, Y. K., Park, S., Choi, J. S., Lee, C. J., et al. (2008). Neuroligin1 is required for normal expression of LTP and associative fear memory in the amygdala of adult animals. Proc. Natl. Acad. Sci. U.S.A. 105, 9087-9092. doi: 10.1073/pnas.0803448105

Kim, R. H., Peters, M., Jang, Y., Shi, W., Pintilie, M., Fletcher, G. C., et al. (2005). DJ-1, a novel regulator of the tumor suppressor PTEN. Cancer Cell 7, 263-273. doi: $10.1016 /$ j.ccr.2005.02.010

Kirkpatrick, L. L., McIlwain, K. A., and Nelson, D. L. (2001). Comparative genomic sequence analysis of the FXR gene family: FMR1, FXR1, and FXR2. Genomics 78, 169-177. doi: 10.1006/geno.2001.6667 
Kitada, T., Pisani, A., Porter, D. R., Yamaguchi, H., Tscherter, A., Martella, G., et al. (2007). Impaired dopamine release and synaptic plasticity in the striatum of PINK1-deficient mice. Proc. Natl. Acad. Sci. U.S.A. 104, 11441-11446. doi: 10.1073/pnas.0702717104

Kitada, T., Tong, Y., Gautier, C. A., and Shen, J. (2009). Absence of nigral degeneration in aged parkin/DJ-1/PINK1 triple knockout mice. J. Neurochem. 111, 696-702. doi: 10.1111/j.1471-4159.2009.06350.x

Koekkoek, S. K., Yamaguchi, K., Milojkovic, B. A., Dortland, B. R., Ruigrok, T. J., Maex, R., et al. (2005). Deletion of FMR1 in Purkinje cells enhances parallel fiber LTD, enlarges spines, and attenuates cerebellar eyelid conditioning in Fragile X syndrome. Neuron 47, 339-352. doi: 10.1016/j.neuron.2005. 07.005

Koike, H., Arguello, P. A., Kvajo, M., Karayiorgou, M., and Gogos, J. A. (2006). Discl is mutated in the $129 \mathrm{~S} 6 / \mathrm{SvEv}$ strain and modulates working memory in mice. Proc. Natl. Acad. Sci. U.S.A. 103, 3693-3697. doi: 10.1073/pnas.0511189103

Kooy, R. F., D’Hooge, R., Reyniers, E., Bakker, C. E., Nagels, G., De Boulle, K., et al. (1996). Transgenic mouse model for the fragile X syndrome. Am. J. Med. Genet. 64, 241-245. doi: 10.1002/(SICI)1096-8628(19960809)64:2<241::AIDAJMG1 > 3.0.CO;2-X

Kremer, E. J., Pritchard, M., Lynch, M., Yu, S., Holman, K., Baker, E., et al. (1991a). Mapping of DNA instability at the fragile $\mathrm{X}$ to a trinucleotide repeat sequence p(CCG)n. Science 252, 1711-1714. doi: 10.1126/science.1675488

Kremer, E. J., Yu, S., Pritchard, M., Nagaraja, R., Heitz, D., Lynch, M., et al. (1991b). Isolation of a human DNA sequence which spans the fragile X. Am. J. Hum. Genet. 49, 656-661.

Kumar, R., Gururaj, A. E., and Barnes, C. J. (2006). p21-activated kinases in cancer. Nat. Rev. Cancer 6, 459-471. doi: 10.1038/nrc1892

Kvajo, M., McKellar, H., Drew, L. J., Lepagnol-Bestel, A. M., Xiao, L., Levy, R. J., et al. (2011). Altered axonal targeting and short-term plasticity in the hippocampus of Disc1 mutant mice. Proc. Natl. Acad. Sci. U.S.A. 108, E1349E1358. doi: 10.1073/pnas.1114113108

Lee, F. H., Zai, C. C., Cordes, S. P., Roder, J. C., and Wong, A. H. (2013). Abnormal interneuron development in disrupted-in-schizophrenia-1 L100P mutant mice. Mol. Brain 6:20.

Lee, V. M., Goedert, M., and Trojanowski, J. Q. (2001). Neurodegenerative tauopathies. Annu. Rev. Neurosci. 24, 1121-1159. doi: 10.1146/annurev.neuro.24.1.1121

Lev, N., Roncevich, D., Ickowicz, D., Melamed, E., and Offen, D. (2007). Role of DJ-1 in parkinson's disease. J. Mol. Neurosci. 31:307.

Levy-Lahad, E., Wasco, W., Poorkaj, P., Romano, D. M., Oshima, J., Pettingell, W. H., et al. (1995). Candidate gene for the chromosome 1 familial Alzheimer's disease locus. Science 269, 973-977. doi: 10.1126/science.7638621

Lewis, J., Dickson, D. W., Lin, W. L., Chisholm, L., Corral, A., Jones, G., et al. (2001). Enhanced neurofibrillary degeneration in transgenic mice expressing mutant tau and APP. Science 293, 1487-1491. doi: 10.1126/science.1058189

Lewis, J., McGowan, E., Rockwood, J., Melrose, H., Nacharaju, P., Van Slegtenhorst, M., et al. (2000). Neurofibrillary tangles, amyotrophy and progressive motor disturbance in mice expressing mutant $(\mathrm{P} 301 \mathrm{~L})$ tau protein. Nat. Genet. 25, 402-405. doi: 10.1038/78078

Li, T., Yang, D., Sushchky, S., Liu, Z., and Smith, W. W. (2011). Models for LRRK2Linked Parkinsonism. Parkinsons Dis. 2011:942412. doi: 10.4061/2011/942412

Li, X., Patel, J. C., Wang, J., Avshalumov, M. V., Nicholson, C., Buxbaum, J. D., et al. (2010). Enhanced striatal dopamine transmission and motor performance with LRRK2 overexpression in mice is eliminated by familial Parkinson's disease mutation G2019S. J. Neurosci. 30, 1788-1797. doi: 10.1523/JNEUROSCI.560409.2010

Li, Y., Liu, W., Oo, T. F., Wang, L., Tang, Y., Jackson-Lewis, V., et al. (2009). Mutant LRRK2(R1441G) BAC transgenic mice recapitulate cardinal features of Parkinson's disease. Nat. Neurosci. 12, 826-828. doi: 10.1038/nn.2349

Liang, J., Xu, W., Hsu, Y. T., Yee, A. X., Chen, L., and Sudhof, T. C. (2015). Conditional neuroligin-2 knockout in adult medial prefrontal cortex links chronic changes in synaptic inhibition to cognitive impairments. Mol. Psychiatry 20, 850-859. doi: 10.1038/mp.2015.31

Lin, X., Parisiadou, L., Gu, X. L., Wang, L., Shim, H., Sun, L., et al. (2009). Leucinerich repeat kinase 2 regulates the progression of neuropathology induced by Parkinson's-disease-related mutant alpha-synuclein. Neuron 64, 807-827. doi: 10.1016/j.neuron.2009.11.006
Lipina, T. V., Wang, M., Liu, F., and Roder, J. C. (2012). Synergistic interactions between PDE4B and GSK-3: DISC1 mutant mice. Neuropharmacology 62, 1252-1262. doi: 10.1016/j.neuropharm.2011.02.020

Liu, H. F., Lu, S., Ho, P. W., Tse, H. M., Pang, S. Y., Kung, M. H., et al. (2014). LRRK2 R1441G mice are more liable to dopamine depletion and locomotor inactivity. Ann. Clin. Transl. Neurol. 1, 199-208. doi: 10.1002/acn3.45

Lok, K., Zhao, H., Shen, H., Wang, Z., Gao, X., Zhao, W., et al. (2013). Characterization of the APP/PS1 mouse model of Alzheimer's disease in senescence accelerated background. Neurosci. Lett. 557(Pt B), 84-89. doi: 10.1016/j.neulet.2013.10.051

Lu, X. H., Fleming, S. M., Meurers, B., Ackerson, L. C., Mortazavi, F., Lo, V., et al. (2009). Bacterial artificial chromosome transgenic mice expressing a truncated mutant parkin exhibit age-dependent hypokinetic motor deficits, dopaminergic neuron degeneration, and accumulation of proteinase K-resistant alphasynuclein. J. Neurosci. 29, 1962-1976. doi: 10.1523/JNEUROSCI.535108.2009

Ma, L., Liu, Y., Ky, B., Shughrue, P. J., Austin, C. P., and Morris, J. A. (2002). Cloning and characterization of Disc1, the mouse ortholog of DISC1 (Disrupted-in-Schizophrenia 1). Genomics 80, 662-672. doi: 10.1006/geno.2002.7012

Mandel, J. L., and Chelly, J. (2004). Monogenic X-linked mental retardation: is it as frequent as currently estimated? The paradox of the ARX (Aristaless X) mutations. Eur. J. Hum. Genet. 12, 689-693. doi: 10.1038/sj.ejhg.5201247

Manser, E., Leung, T., and Lim, L. (1995). Purification and assay of kinases that interact with Rac/Cdc42. Methods Enzymol. 256, 215-227. doi: 10.1016/00766879(95)56026-2

Masliah, E., and Hansen, L. A. (2012). Alzheimer disease: AD pathologyemerging subtypes or age-of-onset spectrum? Nat. Rev. Neurol. 8, 11-12. doi: 10.1038/nrneurol.2011.205

Masliah, E., Rockenstein, E., Veinbergs, I., Mallory, M., Hashimoto, M., Takeda, A., et al. (2000). Dopaminergic loss and inclusion body formation in alphasynuclein mice: implications for neurodegenerative disorders. Science 287, 1265-1269. doi: 10.1126/science.287.5456.1265

Melrose, H. L., Dachsel, J. C., Behrouz, B., Lincoln, S. J., Yue, M., Hinkle, K. M., et al. (2010). Impaired dopaminergic neurotransmission and microtubuleassociated protein tau alterations in human LRRK2 transgenic mice. Neurobiol. Dis. 40, 503-517. doi: 10.1016/j.nbd.2010.07.010

Meng, J., Meng, Y., Hanna, A., Janus, C., and Jia, Z. (2005). Abnormal long-lasting synaptic plasticity and cognition in mice lacking the mental retardation gene Pak3. J. Neurosci. 25, 6641-6650. doi: 10.1523/JNEUROSCI.0028-05.2005

Meng, Y., Takahashi, H., Meng, J., Zhang, Y., Lu, G., Asrar, S., et al. (2004). Regulation of $\mathrm{ADF} /$ cofilin phosphorylation and synaptic function by LIM-kinase. Neuropharmacology 47, 746-754. doi: 10.1016/j.neuropharm.2004.06.030

Meng, Y., Zhang, Y., Tregoubov, V., Janus, C., Cruz, L., Jackson, M., et al. (2002). Abnormal spine morphology and enhanced LTP in LIMK-1 knockout mice. Neuron 35, 121-133. doi: 10.1016/S0896-6273(02)00758-4

Merla, G., Brunetti-Pierri, N., Micale, L., and Fusco, C. (2010). Copy number variants at Williams-Beuren syndrome 7q11.23 region. Hum. Genet. 128, 3-26. doi: 10.1007/s00439-010-0827-2

Mervis, C. B., and John, A. E. (2010). Cognitive and behavioral characteristics of children with Williams syndrome: implications for intervention approaches. Am. J. Med. Genet. C Semin. Med. Genet. 154C, 229-248. doi: 10.1002/ajmg.c.30263

Mervis, C. B., and Velleman, S. L. (2011). Children with Williams Syndrome: language, cognitive, and behavioral characteristics and their implications for intervention. Perspect. Lang. Learn. Educ. 18, 98-107. doi: 10.1044/lle 18.3.98

Meyer, D., and Birchmeier, C. (1995). Multiple essential functions of neuregulin in development. Nature 378, 386-390. doi: 10.1038/378386a0

Mientjes, E. J., Nieuwenhuizen, I., Kirkpatrick, L., Zu, T., HoogeveenWesterveld, M., Severijnen, L., et al. (2006). The generation of a conditional Fmr1 knock out mouse model to study Fmrp function in vivo. Neurobiol. Dis. 21, 549-555. doi: 10.1016/j.nbd.2005.08.019

Millar, J. K., Pickard, B. S., Mackie, S., James, R., Christie, S., Buchanan, S. R., et al. (2005). DISC1 and PDE4B are interacting genetic factors in schizophrenia that regulate cAMP signaling. Science 310, 1187-1191. doi: 10.1126/science.11 12915 
Missler, M., Zhang, W., Rohlmann, A., Kattenstroth, G., Hammer, R. E., Gottmann, K., et al. (2003). Alpha-neurexins couple $\mathrm{Ca} 2+$ channels to synaptic vesicle exocytosis. Nature 423, 939-948. doi: 10.1038/nature 01755

Moechars, D., Dewachter, I., Lorent, K., Reverse, D., Baekelandt, V., Naidu, A., et al. (1999). Early phenotypic changes in transgenic mice that overexpress different mutants of amyloid precursor protein in brain. J. Biol. Chem. 274, 6483-6492. doi: $10.1074 /$ jbc. 274.10 .6483

Mohn, A. R., Gainetdinov, R. R., Caron, M. G., and Koller, B. H. (1999). Mice with reduced NMDA receptor expression display behaviors related to schizophrenia. Cell 98, 427-436. doi: 10.1016/S0092-8674(00)81972-8

Morris, J. A., Kandpal, G., Ma, L., and Austin, C. P. (2003). DISC1 (DisruptedIn-Schizophrenia 1) is a centrosome-associated protein that interacts with MAP1A, MIPT3, ATF4/5 and NUDEL: regulation and loss of interaction with mutation. Hum. Mol. Genet. 12, 1591-1608. doi: 10.1093/hmg/ ddg 162

Morris, M., Knudsen, G. M., Maeda, S., Trinidad, J. C., Ioanoviciu, A., Burlingame, A. L., et al. (2015). Tau post-translational modifications in wild-type and human amyloid precursor protein transgenic mice. Nat. Neurosci. 18, 1183-1189. doi: 10.1038/nn.4067

Naisbitt, S., Kim, E., Tu, J. C., Xiao, B., Sala, C., Valtschanoff, J., et al. (1999). Shank, a novel family of postsynaptic density proteins that binds to the NMDA receptor/PSD-95/GKAP complex and cortactin. Neuron 23, 569-582. doi: 10.1016/S0896-6273(00)80809-0

Naslund, J., Haroutunian, V., Mohs, R., Davis, K. L., Davies, P., Greengard, P., et al. (2000). Correlation between elevated levels of amyloid beta-peptide in the brain and cognitive decline. JAMA 283, 1571-1577. doi: 10.1001/jama.283. 12.1571

Nichols, W. C., Pankratz, N., Hernandez, D., Paisan-Ruiz, C., Jain, S., Halter, C. A., et al. (2005). Genetic screening for a single common LRRK2 mutation in familial Parkinson's disease. Lancet 365, 410-412. doi: 10.1016/S0140-6736(05) 17828-3

No authors (1994). Fmr1 knockout mice: a model to study fragile X mental retardation. The Dutch-Belgian Fragile X Consortium. Cell 78, 23-33.

O’Brien, R. J., and Wong, P. C. (2011). Amyloid precursor protein processing and Alzheimer's disease. Annu. Rev. Neurosci. 34, 185-204. doi: 10.1146/annurevneuro-061010-113613

Oddo, S., Caccamo, A., Kitazawa, M., Tseng, B. P., and LaFerla, F. M. (2003). Amyloid deposition precedes tangle formation in a triple transgenic model of Alzheimer's disease. Neurobiol. Aging 24, 1063-1070. doi: 10.1016/j.neurobiolaging.2003.08.012

O'Donnell, W. T., and Warren, S. T. (2002). A decade of molecular studies of fragile X syndrome. Annu. Rev. Neurosci. 25, 315-338. doi: 10.1146/annurev.neuro.25.112701.142909

O’Tuathaigh, C. M., Babovic, D., O’Meara, G., Clifford, J. J., Croke, D. T., and Waddington, J. L. (2007). Susceptibility genes for schizophrenia: characterisation of mutant mouse models at the level of phenotypic behaviour. Neurosci. Biobehav. Rev. 31, 60-78. doi: 10.1016/j.neubiorev.2006.04.002

Pankratz, N., Nichols, W. C., Elsaesser, V. E., Pauciulo, M. W., Marek, D. K., Halter, C. A., et al. (2009). Alpha-synuclein and familial Parkinson's disease. Mov. Disord. 24, 1125-1131. doi: 10.1002/mds.22524

Parisiadou, L., Xie, C., Cho, H. J., Lin, X., Gu, X. L., Long, C. X., et al. (2009). Phosphorylation of ezrin/radixin/moesin proteins by LRRK2 promotes the rearrangement of actin cytoskeleton in neuronal morphogenesis. J. Neurosci. 29, 13971-13980. doi: 10.1523/JNEUROSCI.3799-09.2009

Parisiadou, L., Yu, J., Sgobio, C., Xie, C., Liu, G., Sun, L., et al. (2014). LRRK2 regulates synaptogenesis and dopamine receptor activation through modulation of PKA activity. Nat. Neurosci. 17, 367-376. doi: 10.1038/nn.3636

Peca, J., Feliciano, C., Ting, J. T., Wang, W., Wells, M. F., Venkatraman, T. N., et al. (2011). Shank3 mutant mice display autistic-like behaviours and striatal dysfunction. Nature 472, 437-442. doi: 10.1038/nature09965

Penagarikano, O., Abrahams, B. S., Herman, E. I., Winden, K. D., Gdalyahu, A., Dong, H., et al. (2011). Absence of CNTNAP2 leads to epilepsy, neuronal migration abnormalities, and core autism-related deficits. Cell 147, 235-246. doi: 10.1016/j.cell.2011.08.040

Perez, F. A., and Palmiter, R. D. (2005). Parkin-deficient mice are not a robust model of parkinsonism. Proc. Natl. Acad. Sci. U.S.A. 102, 2174-2179. doi: 10.1073/pnas.0409598102
Petersen, R. C., Smith, G. E., Waring, S. C., Ivnik, R. J., Tangalos, E. G., and Kokmen, E. (1999). Mild cognitive impairment: clinical characterization and outcome. Arch. Neurol. 56, 303-308. doi: 10.1001/archneur.56.3.303

Phelan, M. C., Rogers, R. C., Saul, R. A., Stapleton, G. A., Sweet, K., McDermid, H., et al. (2001). 22q13 deletion syndrome. Am. J. Med. Genet. 101, 91-99. doi: 10.1002/1096-8628(20010615)101:2<91::AID-AJMG1340>3.0.CO;2-C

Pietropaolo, S., and Subashi, E. (2014). "Fragile X syndrome," in Behavioral Genetics of the Mouse: Genetic Mouse Models of Neurobehavioural Disorders, eds F. S. S. Pietropaolo and W. E. Crusio (Cambridge: Cambridge University Press).

Plaas, M., Karis, A., Innos, J., Rebane, E., Baekelandt, V., Vaarmann, A., et al. (2008). Alpha-synuclein A30P point-mutation generates age-dependent nigrostriatal deficiency in mice. J. Physiol. Pharmacol. 59, 205-216.

Pober, B. R. (2010). Williams-Beuren syndrome. N. Engl. J. Med. 362, 239-252. doi: 10.1056/NEJMra0903074

Poliak, S., Gollan, L., Martinez, R., Custer, A., Einheber, S., Salzer, J. L., et al. (1999). Caspr2, a new member of the neurexin superfamily, is localized at the juxtaparanodes of myelinated axons and associates with $\mathrm{K}+$ channels. Neuron 24, 1037-1047. doi: 10.1016/S0896-6273(00)81049-1

Polymeropoulos, M. H., Lavedan, C., Leroy, E., Ide, S. E., Dehejia, A., Dutra, A., et al. (1997). Mutation in the alpha-synuclein gene identified in families with Parkinson's disease. Science 276, 2045-2047. doi: 10.1126/science.276.53 21.2045

Rabaneda, L. G., Robles-Lanuza, E., Nieto-Gonzalez, J. L., and Scholl, F. G. (2014). Neurexin dysfunction in adult neurons results in autistic-like behavior in mice. Cell Rep. 8, 338-346. doi: 10.1016/j.celrep.2014.06.022

Radyushkin, K., Hammerschmidt, K., Boretius, S., Varoqueaux, F., El-Kordi, A., Ronnenberg, A., et al. (2009). Neuroligin-3-deficient mice: model of a monogenic heritable form of autism with an olfactory deficit. Genes Brain Behav. 8, 416-425. doi: 10.1111/j.1601-183X.2009.00487.x

Reyniers, L., Del Giudice, M. G., Civiero, L., Belluzzi, E., Lobbestael, E., Beilina, A., et al. (2014). Differential protein-protein interactions of LRRK1 and LRRK2 indicate roles in distinct cellular signaling pathways. J. Neurochem. 131, 239250. doi: 10.1111/jnc. 12798

Rial, D., Castro, A. A., Machado, N., Garcao, P., Goncalves, F. Q., Silva, H. B., et al. (2014). Behavioral phenotyping of Parkin-deficient mice: looking for early preclinical features of Parkinson's disease. PLOS ONE 9:e114216. doi: 10.1371/journal.pone.0114216

Rieker, C., Dev, K. K., Lehnhoff, K., Barbieri, S., Ksiazek, I., Kauffmann, S., et al. (2011). Neuropathology in mice expressing mouse alpha-synuclein. PLoS ONE 6:e24834. doi: 10.1371/journal.pone.0024834

Rockenstein, E., Mallory, M., Hashimoto, M., Song, D., Shults, C. W., Lang, I., et al. (2002). Differential neuropathological alterations in transgenic mice expressing alpha-synuclein from the platelet-derived growth factor and Thy-1 promoters. J. Neurosci. Res. 68, 568-578. doi: 10.1002/jnr.10231

Rodenas-Cuadrado, P., Ho, J., and Vernes, S. C. (2014). Shining a light on CNTNAP2: complex functions to complex disorders. Eur. J. Hum. Genet. 22, 171-178. doi: 10.1038/ejhg.2013.100

Roder, S., Danober, L., Pozza, M. F., Lingenhoehl, K., Wiederhold, K. H., and Olpe, H. R. (2003). Electrophysiological studies on the hippocampus and prefrontal cortex assessing the effects of amyloidosis in amyloid precursor protein 23 transgenic mice. Neuroscience 120, 705-720. doi: 10.1016/S03064522(03)00381-6

Rothwell, P. E., Fuccillo, M. V., Maxeiner, S., Hayton, S. J., Gokce, O., Lim, B. K., et al. (2014). Autism-associated neuroligin-3 mutations commonly impair striatal circuits to boost repetitive behaviors. Cell 158, 198-212. doi: 10.1016/j.cell.2014.04.045

Sachs, N. A., Sawa, A., Holmes, S. E., Ross, C. A., DeLisi, L. E., and Margolis, R. L. (2005). A frameshift mutation in Disrupted in Schizophrenia 1 in an American family with schizophrenia and schizoaffective disorder. Mol. Psychiatry 10, 758-764. doi: 10.1038/sj.mp.4001667

Sanders, S. J., Ercan-Sencicek, A. G., Hus, V., Luo, R., Murtha, M. T., Moreno-DeLuca, D., et al. (2011). Multiple recurrent de novo CNVs, including duplications of the $7 \mathrm{q} 11.23$ Williams syndrome region, are strongly associated with autism. Neuron 70, 863-885. doi: 10.1016/j.neuron.2011.05.002

Satake, W., Nakabayashi, Y., Mizuta, I., Hirota, Y., Ito, C., Kubo, M., et al. (2009). Genome-wide association study identifies common variants at four loci as genetic risk factors for Parkinson's disease. Nat. Genet. 41, 1303-1307. doi: $10.1038 /$ ng.485 
Saura, C. A., Chen, G., Malkani, S., Choi, S. Y., Takashashi, R. H., Zhang, D., et al. (2005). Conditional inactivation of presenilin 1 prevents amyloid accumulation and temporarily rescues contextual and spatial working memroy impairments in amyloid precursor protein transgenic mice. J. Neurosci. 29, 6755-6764. doi: 10.1523/JNEUROSCI.1247-05.2005

Savonenko, A. V., Xu, G. M., Price, D. L., Borchelt, D. R., and Markowska, A. L. (2003). Normal cognitive behavior in two distinct congenic lines of transgenic mice hyperexpressing mutant APP SWE. Neurobiol. Dis. 12, 194-211. doi: 10.1016/S0969-9961(02)00012-8

Scheuner, D., Eckman, C., Jensen, M., Song, X., Citron, M., Suzuki, N., et al. (1996). Secreted amyloid beta-protein similar to that in the senile plaques of Alzheimer's disease is increased in vivo by the presenilin 1 and 2 and APP mutations linked to familial Alzheimer's disease. Nat. Med. 2, 864-870. doi: 10.1038/nm0896-864

Schughart, K., Libert, C., and Kas, M. J. (2013). Controlling complexity: the clinical relevance of mouse complex genetics. Eur. J. Hum. Genet. 21, 1191-1196. doi: 10.1038/ejhg.2013.79

Sherrington, R., Rogaev, E. I., Liang, Y., Rogaeva, E. A., Levesque, G., Ikeda, M., et al. (1995). Cloning of a gene bearing missense mutations in earlyonset familial Alzheimer's disease. Nature 375, 754-760. doi: 10.1038/375 $754 \mathrm{a} 0$

Simon, A. M., Schiapparelli, L., Salazar-Colocho, P., Cuadrado-Tejedor, M., Escribano, L., Lopez de Maturana, R., et al. (2009). Overexpression of wild-type human APP in mice causes cognitive deficits and pathological features unrelated to Abeta levels. Neurobiol. Dis. 33, 369-378. doi: 10.1016/j.nbd.2008.11.005

Singleton, A. B. (2005). Altered alpha-synuclein homeostasis causing Parkinson's disease: the potential roles of dardarin. Trends Neurosci. 28, 416-421. doi: 10.1016/j.tins.2005.05.009

Soares, D. C., Carlyle, B. C., Bradshaw, N. J., and Porteous, D. J. (2011). DISC1: structure, function, and therapeutic potential for major mental illness. ACS Chem. Neurosci. 2, 609-632. doi: 10.1021/cn200062k

Sorensen, E. M., Bertelsen, F., Weikop, P., Skovborg, M. M., Banke, T., Drasbek, K. R., et al. (2015). Hyperactivity and lack of social discrimination in the adolescent Fmr1 knockout mouse. Behav. Pharmacol. 26, 733-740. doi: 10.1097/FBP.0000000000000152

Speed, H. E., Kouser, M., Xuan, Z., Reimers, J. M., Ochoa, C. F., Gupta, N., et al. (2015). Autism-associated insertion mutation (InsG) of Shank3 Exon 21 causes impaired synaptic transmission and behavioral deficits. J. Neurosci. 35, 9648-9665. doi: 10.1523/JNEUROSCI.3125-14.2015

Spencer, C. M., Serysheva, E., Yuva-Paylor, L. A., Oostra, B. A., Nelson, D. L., and Paylor, R. (2006). Exaggerated behavioral phenotypes in Fmr1/Fxr2 double knockout mice reveal a functional genetic interaction between Fragile X-related proteins. Hum. Mol. Genet. 15, 1984-1994. doi: 10.1093/hmg/ ddl121

Sperling, R. A., Aisen, P. S., Beckett, L. A., Bennett, D. A., Craft, S., Fagan, A. M., et al. (2011). Toward defining the preclinical stages of Alzheimer's disease: recommendations from the National Institute on Aging-Alzheimer's Association workgroups on diagnostic guidelines for Alzheimer's disease. Alzheimers Dement. 7, 280-292. doi: 10.1016/j.jalz.2011.03.003

Spillantini, M. G., Crowther, R. A., Jakes, R., Cairns, N. J., Lantos, P. L., and Goedert, M. (1998). Filamentous alpha-synuclein inclusions link multiple system atrophy with Parkinson's disease and dementia with Lewy bodies. Neurosci. Lett. 251, 205-208. doi: 10.1016/S0304-3940(98) 00504-7

St Clair, D., Blackwood, D., Muir, W., Carothers, A., Walker, M., Spowart, G., et al. (1990). Association within a family of a balanced autosomal translocation with major mental illness. Lancet 336, 13-16. doi: 10.1016/0140-6736(90) 91520-K

Stefansson, H., Sigurdsson, E., Steinthorsdottir, V., Bjornsdottir, S., Sigmundsson, T., Ghosh, S., et al. (2002). Neuregulin 1 and susceptibility to schizophrenia. Am. J. Hum. Genet. 71, 877-892. doi: 10.1086/ 342734

Stromme, P., Bjornstad, P. G., and Ramstad, K. (2002). Prevalence estimation of Williams syndrome. J. Child Neurol. 17, 269-271. doi: $10.1177 / 088307380201700406$

Sturchler-Pierrat, C., Abramowski, D., Duke, M., Wiederhold, K. H., Mistl, C., Rothacher, S., et al. (1997). Two amyloid precursor protein transgenic mouse models with Alzheimer disease-like pathology. Proc. Natl. Acad. Sci. U.S.A. 94, 13287-13292. doi: 10.1073/pnas.94.24.13287

Sudhof, T. C. (2008). Neuroligins and neurexins link synaptic function to cognitive disease. Nature 455, 903-911. doi: 10.1038/nature07456

Sumi, T., Matsumoto, K., Takai, Y., and Nakamura, T. (1999). Cofilin phosphorylation and actin cytoskeletal dynamics regulated by rho- and Cdc42activated LIM-kinase 2. J. Cell Biol. 147, 1519-1532. doi: 10.1083/jcb.147. 7.1519

Tabuchi, K., Blundell, J., Etherton, M. R., Hammer, R. E., Liu, X., Powell, C. M., et al. (2007). A neuroligin-3 mutation implicated in autism increases inhibitory synaptic transmission in mice. Science 318, 71-76. doi: 10.1126/science.11 46221

Tabuchi, K., and Sudhof, T. C. (2002). Structure and evolution of neurexin genes: insight into the mechanism of alternative splicing. Genomics 79, 849-859. doi: 10.1006/geno.2002.6780

Tassabehji, M., Metcalfe, K., Fergusson, W. D., Carette, M. J., Dore, J. K., Donnai, D., et al. (1996). LIM-kinase deleted in Williams syndrome. Nat. Genet. 13, 272-273. doi: 10.1038/ng0796-272

Thiruchelvam, M. J., Powers, J. M., Cory-Slechta, D. A., and Richfield, E. K. (2004). Risk factors for dopaminergic neuron loss in human alpha-synuclein transgenic mice. Eur. J. Neurosci. 19, 845-854. doi: 10.1111/j.0953-816X.2004. 03139.x

Todorovski, Z., Asrar, S., Liu, J., Saw, N. M., Joshi, K., Cortez, M. A., et al. (2015). LIMK1 regulates long-term memory and synaptic plasticity via the transcriptional factor CREB. Mol. Cell. Biol. 35, 1316-1328. doi: 10.1128/MCB.01263-14

Tong, Y., and Shen, J. (2009). alpha-synuclein and LRRK2: partners in crime. Neuron 64, 771-773. doi: 10.1016/j.neuron.2009.12.017

Uchino, S., and Waga, C. (2013). SHANK3 as an autism spectrum disorderassociated gene. Brain Dev. 35, 106-110. doi: 10.1016/j.braindev.2012. 05.013

Um, J. W., Stichel-Gunkel, C., Lubbert, H., Lee, G., and Chung, K. C. (2009). Molecular interaction between parkin and PINK1 in mammalian neuronal cells. Mol. Cell. Neurosci. 40, 421-432. doi: 10.1016/j.mcn.2008.12.010

van der Putten, H., Wiederhold, K. H., Probst, A., Barbieri, S., Mistl, C., Danner, S., et al. (2000). Neuropathology in mice expressing human alpha-synuclein. J. Neurosci. 20, 6021-6029.

Varoqueaux, F., Aramuni, G., Rawson, R. L., Mohrmann, R., Missler, M., Gottmann, K., et al. (2006). Neuroligins determine synapse maturation and function. Neuron 51, 741-754. doi: 10.1016/j.neuron.2006. 09.003

Verkerk, A. J., Pieretti, M., Sutcliffe, J. S., Fu, Y. H., Kuhl, D. P., Pizzuti, A., et al. (1991). Identification of a gene (FMR-1) containing a CGG repeat coincident with a breakpoint cluster region exhibiting length variation in fragile X syndrome. Cell 65, 905-914. doi: 10.1016/0092-8674(91) 90397-H

Vigo-Pelfrey, C., Lee, D., Keim, P., Lieberburg, I., and Schenk, D. B. (1993). Characterization of beta-amyloid peptide from human cerebrospinal fluid. J. Neurochem. 61, 1965-1968. doi: 10.1111/j.1471-4159.1993.tb 09841.x

West, A. B., Moore, D. J., Biskup, S., Bugayenko, A., Smith, W. W., Ross, C. A., et al. (2005). Parkinson's disease-associated mutations in leucine-rich repeat kinase 2 augment kinase activity. Proc. Natl. Acad. Sci. U.S.A. 102, 16842-16847. doi: 10.1073/pnas.0507360102

Winner, B., Melrose, H. L., Zhao, C., Hinkle, K. M., Yue, M., Kent, C., et al. (2011). Adult neurogenesis and neurite outgrowth are impaired in LRRK2 G2019S mice. Neurobiol. Dis. 41, 706-716. doi: 10.1016/j.nbd.2010. 12.008

Yang, N., Higuchi, O., Ohashi, K., Nagata, K., Wada, A., Kangawa, K., et al. (1998). Cofilin phosphorylation by LIM-kinase 1 and its role in Rac-mediated actin reorganization. Nature 393, 809-812. doi: 10.1038/ 31735

Yu, H., Saura, C. A., Choi, S. Y., Sun, L. D., Yang, X., Handler, M., et al. (2001). APP processing and synaptic plasticity in presenilin-1 conditional knock-out mice. Neuron 31, 713-726. doi: 10.1016/S0896-6273(01) 00417-2

Yuhas, J., Cordeiro, L., Tassone, F., Ballinger, E., Schneider, A., Long, J. M., et al. (2011). Brief report: sensorimotor gating in idiopathic autism and autism 
associated with fragile X syndrome. J. Autism. Dev. Disord. 41, 248-253. doi: 10.1007/s10803-010-1040-9

Zhang, B. R., Hu, Z. X., Yin, X. Z., Cai, M., Zhao, G. H., Liu, Z. R., et al. (2010). Mutation analysis of parkin and PINK1 genes in early-onset Parkinson's disease in China. Neurosci. Lett. 477, 19-22. doi: 10.1016/j.neulet.2010. 04.026

Zhao, L., Ma, Q. L., Calon, F., Harris-White, M. E., Yang, F., Lim, G. P., et al. (2006). Role of p21-activated kinase pathway defects in the cognitive deficits of Alzheimer disease. Nat. Neurosci. 9, 234-242. doi: 10.1038/ nn 1630

Zhou, H., Falkenburger, B. H., Schulz, J. B., Tieu, K., Xu, Z., and Xia, X. G. (2007). Silencing of the Pink1 gene expression by conditional RNAi does not induce dopaminergic neuron death in mice. Int. J. Biol. Sci. 3, 242-250. doi: $10.7150 /$ ijbs.3.242
Conflict of Interest Statement: The authors declare that the research was conducted in the absence of any commercial or financial relationships that could be construed as a potential conflict of interest.

The handling Editor declared a shared affiliation, though no other collaboration, with the authors and states that the process nevertheless met the standards of a fair and objective review.

Copyright (c) 2016 Leung and Jia. This is an open-access article distributed under the terms of the Creative Commons Attribution License (CC BY). The use, distribution or reproduction in other forums is permitted, provided the original author (s) or licensor are credited and that the original publication in this journal is cited, in accordance with accepted academic practice. No use, distribution or reproduction is permitted which does not comply with these terms. 